\title{
Dual Roles for c-Jun N-Terminal Kinase in Developmental and Stress Responses in Cerebellar Granule Neurons
}

\author{
Eleanor T. Coffey, ${ }^{1,2}$ Vesa Hongisto, ${ }^{1,2}$ Martin Dickens, ${ }^{3}$ Roger J. Davis, ${ }^{4}$ and Michael J. Courtney ${ }^{1,2,5}$ \\ 1 Turku Centre for Biotechnology, Åbo Akademi University and University of Turku, BioCity, FIN-20521 Turku, Finland, \\ 2Department of Biochemistry and Pharmacy, Åbo Akademi University, BioCity, FIN-20521 Turku, Finland, ${ }^{3}$ Department of \\ Biochemistry, University of Leicester, Leicester LE17RH, United Kingdom, ${ }^{4}$ Howard Hughes Medical Institute, Department \\ of Biochemistry and Molecular Biology, University of Massachusetts, Worcester, Massachusetts 01655, and ${ }^{5} \mathrm{~A}$. I. Virtanen \\ Institute, University of Kuopio, FIN-70211 Kuopio, Finland
}

C-Jun N-terminal kinases (JNKs) typically respond strongly to stress, are implicated in brain development, and are believed to mediate neuronal apoptosis. Surprisingly, however, JNK does not respond characteristically to stress in cultured cerebellar granule (CBG) neurons, a widely exploited CNS model for studies of death and development, despite the regulation of its substrate c-Jun. To understand this anomaly, we characterized JNK regulation in CBG neurons. We find that the specific activity of CBG JNK is elevated considerably above that from neuron-like cell lines (SH-SY5Y, PC12); however, similar elevated activities are found in brain extracts. This activity does not result from cellular stress because the stress-activated protein kinase p38 is not activated. We identify a minor stress-sensitive pool of JNK that translocates with mitogen-activated protein kinase kinase-4 (MKK4) into the nucleus. However, the major pool of total activity is cytoplasmic, residing largely in the neurites, suggesting a non-nuclear role for JNK in neurons. A third JNK pool is colocal- ized with MKK7 in the nucleus, and specific activities of both increase during neuritogenesis, nuclear JNK activity increasing 10-fold, whereas C-Jun expression and activity decrease. A role for JNK during differentiation is supported by modulation of neuritic architecture after expression of dominant inhibitory regulators of the JNK pathway. Channeling of JNK signaling away from c-Jun during differentiation is consistent with the presence in the nucleus of the JNK/MKK7 scaffold protein JNK-interacting protein, which inhibits JNK-C-Jun interaction. We propose a model in which distinct pools of JNK serve different functions, providing a basis for understanding multifunctional JNK signaling in differentiating neurons.

Key words: cerebellar granule neuron; stress-activated protein kinase; JNK; JIP; MKK4; MKK7; p38; c-Jun; nuclear translocation; neuronal differentiation; dominant negative; neuronal morphology
c-Jun N-terminal kinases (JNKs) phosphorylate the transactivation domains of several transcription factors including c-Jun, inducing transcriptional activation. JNKs have been extensively investigated in non-neuronal tissues. Like the related kinase p38, they are also known as stress-activated protein kinases, because their activities typically increase up to more than 10 -fold in response to a wide range of cellular stresses such as treatment with ribosomal inhibitors, osmotic stress, and short wavelength irradiation (Kyriakis et al., 1995; Kyriakis and Avruch, 1996; Iordanov et al., 1997). Ten isoforms of JNK1, JNK2, and the neural JNK3 genes are expressed in brain (Mohit et al., 1995; Gupta et al., 1996). Two JNK kinases, mitogen-activated protein kinase kinase-4 (MKK4) and MKK7, have been cloned (Dérijard et al., 1995; Moriguchi et al., 1997), and these are further diversified by alter-

\footnotetext{
Received Dec. 9, 1999; revised July 24, 2000; accepted July 27, 2000.

This work was supported by the Academy of Finland, the Borg Foundation, the Ella and Georg Ehrnrooths Stiftelse, the Magnus Ehrnrooth Stiftelse, the Finska Vetenskaps Societeten, the Oskar Öflund Stiftelse, and the Wellcome Trust. We thank Eisuke Nishida (Kyoto University, Kyoto, Japan) for providing antiserum to MKK7 for preliminary experiments, John Kyriakis [Massachusetts General Hospital (MGH), Boston, MA] for providing anti-SAPK antiserum and for helpful discussion, James R. Woodgett (Ontario Cancer Institute, Toronto, Canada) for helpful discussion, Arpad Molnar (MGH) for advice on immunofluorescent staining of phospho-JNK, John C. Lee (SmithKline Beecham Pharmaceuticals) for providing SB203580, Jorma Määtta for advice on RT-PCR methods, and Michael Greenberg and Hank Dudek (Harvard University, Boston, MA) for advice on transfection methods. We are grateful to the following people for generous gifts of plasmids: Ron Prywes (Columbia University, New York, NY), John Kyriakis (MGH), James Woodgett (Ontario Cancer Institute, Ontario), Sander van den Heuvel (MGH), Bruce Mayer (Children's Hospital, Boston, MA), Peter Shaw (University of Nottingham, Nottingham, UK), and Joël Raingeaud (Centre National de la Recherche Scientifique, Orsay, France).

Correspondence should be addressed to Eleanor T. Coffey, Turku Centre for Biotechnology, Åbo Akademi University and Turku University, BioCity, P.O. Box 123, FIN-20521 Turku, Finland. E-mail ecoffey@aton.abo.fi.

Copyright (C) 2000 Society for Neuroscience $0270-6474 / 00 / 207602-12 \$ 15.00 / 0$
}

native splicing. These kinases activate JNK by phosphorylation on both tyrosine and threonine residues, after which JNK is understood to translocate to the nucleus, the location of the well characterized JNK substrates transcription factors c-Jun, ATF2, Elk, and Sap1a (Pulverer et al., 1991; Gupta et al., 1995; Janknecht and Hunter, 1997). JNK signaling can be further regulated by JIP (JNK-interacting protein). JIP binds MKK7 and JNK, enhancing JNK activation by MKK7; however, JIP does not interact with MKK4 (Whitmarsh et al., 1998). JIP competes with c-Jun, ATF2, and Elk for JNK binding via its JNK-binding domain (JBD) (Dickens et al., 1997), suggesting that it may channel JNK activity toward alternative substrates that interact with JNK via motifs different from the JBD.

It is widely believed that JNK mediates cellular apoptosis in response to stress (Kyriakis and Avruch, 1996; Ip and Davis, 1998), a role particularly emphasized in neurons and neuron-like cells (Xia et al., 1995) where the JNK phosphorylation sites of c-Jun are required for trophic factor deprivation-induced death (Ham et al., 1995; Watson et al., 1998). It might be expected, therefore, that neuronal JNK would have low basal activity and respond sensitively to apopototic signals. Surprisingly, however, it has been reported that cerebellar granule neuron JNK is nonresponsive to apoptotic stresses (Watson et al., 1998). The literature suggests that JNK activity from CNS neurons may be high (Xu et al., 1997), but no comparison with the well studied JNKs from cell lines has been reported.

In this study we analyze cerebellar granule neuron JNK by methods used to characterize JNK signaling in cell lines. We find that JNK of differentiating neurons displays high constitutive activity that resides predominantly in neurites. This largely masks a minor stress-activatable pool of JNK that exhibits stereotypical behavior, i.e., nuclear translocation on activation, and appears to have preferential access to c-Jun. The constitutively active JNK is 
further activated during differentiation, as are MKK4 and MKK7 activities. Inhibition of JNK activity leads to morphological changes suggesting a role for JNK in regulating neuritic architecture during differentiation. Finally, we present a model whereby distinct JNK pools coordinate to transduce stress and developmental signals to different targets in differentiating neurons.

\section{MATERIALS AND METHODS}

Materials. Polyclonal antibodies against MKK4 (MEK-4, K-18), MKK7 (MEK-7, C-19), p38 (C-20), and monoclonal anti-P63-c-Jun (KM-1) were from Santa Cruz Biotechnology (Santa Cruz, CA). Polyclonal antiserum to SAPK was a gift from John Kyriakis [Massachusetts General Hospital (MGH), Boston, MA). Isoform-specific antibodies to JNK1 (G151-333) and JNK1/2 (G151-666) were from PharMingen (San Diego, CA) and to JNK3/1 were from Upstate Biotechnology (Lake Placid, NY). Phosphospecific antibodies to JNK and p38 were from New England Biolabs (Beverly, MA). Monoclonal anti-c-Jun was from Transduction Labs (Lexington, KY). Monoclonal antibodies to JIP-1 have been described previously (Yasuda et al., 1999). 6-Cyano-7-nitroquinoxaline-2,3-dione (CNQX), $(R S)$ - $\alpha$-Methyl-4-carboxyphenylglycine [(RS)-MCPG], and (5R $10 S)-(+)-5$-methyl-10.11-dihydro-5H-dibenzo[a,d]cyclohepten-5,10-imine/ dizocilpine $[(+)-\mathrm{MK} 801]$ were from Tocris Cookson (Bristol, UK). All other materials were from Sigma (St. Louis, MO), Baker (Deventer, Holland), or Calbiochem (La Jolla, CA).

Cell culture. Cerebellar granule neurons were prepared from 7-d-old rats as described previously (Courtney et al., 1997). This preparation is well characterized and is reported to contain $95 \%$ small interneurons, predominantly granule neurons (Thangnipon et al., 1983). Cells were cultured in minimal essential medium (Life Technologies, Paisley, Scotland) supplemented with $10 \%(\mathrm{v} / \mathrm{v})$ fetal calf serum (Life Technologies), $33 \mathrm{~mm}$ glucose, $2 \mathrm{~mm}$ glutamine, $50 \mathrm{U} / \mathrm{ml}$ penicillin, $50 \mu \mathrm{M}$ streptomycin, and 20 $\mathrm{mm}$ supplementary $\mathrm{KCl}$ (final $25.4 \mathrm{~mm} \mathrm{KCl}$ ), except those in Figures 2 and 6 that were grown without additional KCl. Cells were plated at $250,000 /$ $\mathrm{cm}^{2}$ onto culture surfaces coated with poly-L-lysine $(100 \mu \mathrm{g} / \mathrm{ml}): 35 \mathrm{~mm}$ dishes or wells of 12- or 24-well plates (Costar, Corning, NY, and Greiner $\mathrm{GmbH}$, Solingen, Germany) for kinase assays and immunoblotting, and $10.5 \mathrm{~mm} \times 10.5 \mathrm{~mm}$ coverslips for immunofluorescent staining. Culture medium was replaced after $24 \mathrm{hr}$ with the inclusion of $10 \mu \mathrm{M}$ cytosine arabinofuranoside (Sigma) to reduce non-neuronal proliferation. After this time, fresh culture medium was not re-added to the cells, to avoid serum glutamate-associated toxicity. PC12 cells were cultured on collagencoated dishes in minimal essential medium supplemented with $12.5 \%(\mathrm{v} / \mathrm{v})$ horse serum (Life Technologies), $2.5 \%$ (v/v) fetal calf serum, $2 \mathrm{~mm}$ glutamine, $50 \mathrm{U} / \mathrm{ml}$ penicillin, and $50 \mu \mathrm{M}$ streptomycin. SH-SY5Y cells and HeLa cells were cultured in minimal essential medium containing $10 \%$ (v/v) fetal calf serum, $2 \mathrm{~mm}$ glutamine, and penicillin and streptomycin as above. U937 cells were cultured in RPMI (Life Technologies) containing $10 \%$ (v/v) fetal calf serum, $2 \mathrm{~mm}$ glutamine, and penicillin and streptomycin as above. All cells were cultured in a humidified $5 \% \mathrm{CO}_{2}$ atmosphere at $37^{\circ} \mathrm{C}$.

Transfections and reporter assays. Cerebellar granule neurons on $10.5 \times$ $10.5 \mathrm{~mm}$ coverslips for neurite analysis, in 24-well plates for reporter assays, and in 35-mm dishes for kinase assays were transiently transfected as described previously (Xia et al., 1995; Dudek et al., 1997). Cotransfection at a 1:1 ratio with two visible marker plasmids with similar detection sensitivities, pDsRed (Clontech, Cambridge, UK) and pEGFP-F (Clontech), shows that all transfected cells express both proteins (data not shown). Thus the ratio of 1:3 marker plasmid ( $\beta$-galactosidase) to remaining DNA was used. For morphological studies, cells at $72 \mathrm{hr}$ after plating were transfected with $0.5 \mu \mathrm{g}$ of pCMV- $\beta$-galactosidase as a marker for transfection together with $1.5 \mu \mathrm{g}$ of $\mathrm{pEBG}$ empty vector, pEBGSEK1K129R [a kinase dead mutant of SEK1 (MKK4) (Sánchez et al., 1994)], or pcDNA3-JIP-JBD (Dickens et al., 1997). Forty-eight hours after transfection, cells were fixed and stained as described below. For kinase assays, $3.5 \mathrm{~cm}$ dishes of cerebellar granule neurons at $6 \mathrm{~d}$ in vitro (DIV) (an age when transfection efficiency is optimal) were transfected with $1.25 \mu \mathrm{g}$ JN K1 $\alpha 1,7.5 \mu \mathrm{g}$ SEK1KR or JIP-JBD as indicated, and $1.25 \mu \mathrm{g}$ pEGFP$\mathrm{C} 1$. The amount of total DNA was equalized in each sample using pEBG empty vector. At $28 \mathrm{hr}$ after transfection, cells were lysed as described for immune-complex kinase assays, and the activity of pEBG-JNK1 $\alpha 1$ was measured. For reporter assays, 9 DIV cells were transfected with a firefly luciferase reporter plasmid driven by five GAL4 elements in tandem: pGL3-G5E4D38 (Griffiths et al., 1998), a plasmid expressing a fusion protein of the p38 $\alpha$-specific substrate MEF2A with the DNA binding domain of GAL4 (Han and Prywes, 1995), and pRL-CMV (Promega, Madison, WI), expressing sea pansy luciferase as an internal standard against which signals were normalized, and either pcDNA3-MKK6E (Raingeaud et al., 1996) expressing a constitutively active MKK6 and pEBGp38 $\alpha$ (Meyer et al., 1999) or empty vector pCMV (van den Heuvel and Harlow, 1993) as indicated. Empty vector pCMV was added to equalize transfections to $2 \mu \mathrm{g}$ total DNA/well. Twenty hours after transfection cells were lysed in passive lysis buffer (Promega). Firefly (reporter) and Renilla (internal standard) luciferase activities were assayed with the dual luciferase assay kit (Promega) according to the manufacturer's instructions.

Plasmids. pEBG-JNK1 $\alpha 1$ was constructed by inserting JNK1 $\alpha 1$, pre- pared by PCR-based procedures from pcDNA3-JNK1 $\alpha 1$ (Gupta et al., 1996), into the BamHI site of pEBG. All other plasmids were generous gifts from John Kyriakis (MGH, Boston), Peter Shaw (University of Nottingham, UK), Ron Prywes, (Columbia University, New York), Joël Raingeaud (Centre National de la Recherche Scientifique, Orsay, France), Bruce Mayer (Children's Hospital, Boston), and Sander van den Heuvel, (MGH, Boston).

Tissue extract preparation. Tissues from Sprague Dawley rats at postnatal days $8,9,10,13$, and 25 were rapidly extracted subsequent to decapitation and snap-frozen in liquid $\mathrm{N}_{2}$. This method maintains the JNK activity status of brain tissues; it has previously been used to show ischemiainduced activation of JNK in brain (Herdegen et al., 1998). Frozen tissues were homogenized in ice-cold lysis buffer (see below) and precleared by centrifugation at $10,000 \times g$ for $15 \mathrm{~min}$. Samples for immunoblotting were normalized for protein using the Bradford method (Bradford, 1976) and resuspended in $4 \times$ Laemmli sample buffer [ $1 \times$ : $62.5 \mathrm{~mm}$ Tris-HCl, pH 6.8 , $2 \% \operatorname{SDS}(\mathrm{w} / \mathrm{v}), 5 \%$ 2-mercaptoethanol, $10 \%$ glycerol $(\mathrm{v} / \mathrm{v})$, and $0.001 \%$ bromophenol blue $(\mathrm{w} / \mathrm{v})]$.

Immune-complex kinase assays. After treatment, cerebellar granule neurons, PC12 cells, SHSY5Y cells, or U937 cells were washed twice in ice-cold PBS and lysed on ice in $500 \mu$ l of lysis buffer [20 mM HEPES, pH 7.4, 2 mM EGTA, $50 \mathrm{~mm} \beta$-glycerophosphate, $1 \mathrm{~mm}$ dithiothreitol (DTT), $1 \mathrm{~mm} \mathrm{Na} \mathrm{VO}_{4}, 1 \%$ Triton X-100, $10 \%$ glycerol, $1 \mathrm{~mm}$ benzamidine, $50 \mathrm{~mm}$ $\mathrm{NaF}, 1 \mu \mathrm{g} / \mathrm{ml}$ of leupeptin, pepstatin, and aprotinin and $100 \mu \mathrm{g} / \mathrm{ml}$ PMSF]. After homogenization and centrifugation $(10,000 \times g)$ at $4^{\circ} \mathrm{C}$ for $15 \mathrm{~min}$, supernatants were normalized for total protein or for kinase expression in the case of specific activity measurements. Normalized lysates were incubated with anti-SAPK serum for $2 \mathrm{hr}$ followed by $1 \mathrm{hr}$ incubation with 20 $\mu \mathrm{l}$ of $50 \%$ protein A Sepharose or, for transfected cells, with $10 \mu \mathrm{l}$ S-hexylglutathione agarose (Sigma). Immobilized kinase complexes were washed three times with lysis buffer, three times with $\mathrm{LiCl}$ buffer $[500 \mathrm{~mm}$ $\mathrm{LiCl}, 100 \mathrm{~mm}$ Tris, $\mathrm{pH} 7.6,0.1 \%$ Triton $\mathrm{X}-100$, and $1 \mathrm{~mm}$ DTT], and three times with kinase buffer [20 mM MOPS, pH 7.2, 2 mM EGTA, $10 \mathrm{~mm}$ $\mathrm{MgCl}_{2}, 1 \mathrm{mM} \mathrm{DTT}$, and $0.1 \%(\mathrm{v} / \mathrm{v})$ Triton X-100]. Kinase assays were performed in kinase buffer supplemented with $50 \mu \mathrm{M}$ ATP, $5 \mu \mathrm{Ci}$ $\left[\gamma^{32} \mathrm{P}\right]$ ATP (Amersham International), and $6 \mu \mathrm{g}$ of glutathione $S$-transferase-c-Jun (5-89)/sample for $30 \mathrm{~min}$ at $30^{\circ} \mathrm{C}$. Reactions were stopped by addition of $4 \times$ Laemmli sample buffer. Samples were resolved on SDSpolyacrylamide gels and exposed to film, typically for 2-4 hr. Nonsaturated films were digitized by flat-bed scanning followed by quantification using imaging software developed by the authors. Recombinant GST-c-Jun(589) was prepared as described previously (Berberich et al., 1996). To measure MKK4/7 activities, two-step immune-complex assays were performed. Cells were lysed as for JNK assays, and where specific activities were to be measured, lysates were normalized for kinase expression. Immunoprecipitation was essentially the same except that $1 \mu \mathrm{g}$ of antiMKK4 or $2 \mu \mathrm{g}$ of anti-MKK7 was used for $0.5 \mathrm{ml}$ cell lysate. After washing, immune complexes were incubated in kinase buffer supplemented with $30 \mathrm{mM} \mathrm{MgCl} 2,10 \mathrm{mM} \mathrm{MnCl} \mathrm{M}_{2}, 50 \mu \mathrm{M}$ ATP, and recombinant SAPK- $\beta 1$ (prepared by thrombin cleavage from a GST fusion protein) for $20 \mathrm{~min}$ at $30^{\circ} \mathrm{C}$. The second step of the reaction, initiated by addition of ${ }^{32} \mathrm{P}-\gamma$-ATP and $5 \mu \mathrm{g}$ GST-c-Jun(5-89), was also for $20 \mathrm{~min}$ at $30^{\circ} \mathrm{C}$. Phosphorylation of c-Jun(5-89) by MKK4/7-activated recombinant SAPK- $\beta 1$ was detected by autoradiography.

Alkaline phosphatase treatment. Selected JNK immune complexes were incubated with or without alkaline phosphatase $(100 \mathrm{U})$ for $15 \mathrm{~min}$ at $37^{\circ} \mathrm{C}$ as described previously (Park et al., 1995). After phosphatase treatment, immune complexes were collected and washed three times in lysis buffer containing phosphatase inhibitors, three times in $\mathrm{LiCl}$ buffer, and three times in kinase buffer. Samples were then assayed for kinase activity as described above.

Nuclear isolation. Nuclei were prepared as described previously (Park et al., 1995) with some modifications. After stimulation, cells were washed three times in ice-cold PBS $+1 \mathrm{mM} \mathrm{MgCl}_{2}$, and lysed in $20 \mathrm{~mm}$ HEPES, pH 7.4, $10 \mathrm{~mm} \mathrm{NaCl}, 3 \mathrm{~mm} \mathrm{MgCl}_{2}, 2.5 \mathrm{~mm}$ EGTA, $0.1 \mathrm{~mm}$ DTT, $50 \mathrm{~mm}$ $\mathrm{NaF}, 1 \mathrm{~mm} \mathrm{Na} \mathrm{VO}_{4}, 1 \mathrm{~mm} \mathrm{PMSF}$, and $5 \mu \mathrm{g} / \mathrm{ml}$ of leupeptin, pepstatin, and aprotinin. Nonidet P-40 (NP-40) was added to a final concentration of $0.05 \%$, and cells were incubated at $4^{\circ} \mathrm{C}$ for $10 \mathrm{~min}$. Samples were centrifuged at $300 \times g$ for $10 \mathrm{~min}$ at $4^{\circ} \mathrm{C}$. Nuclear pellets were washed in lysis buffer without NP-40. Samples were quantitated for protein and solubilized in Laemmli buffer, and equal proportions (unless indicated otherwise) of nuclear and cytosolic fractions were resolved by SDS-PAGE.

Immunoblot analysis and quantification. Cells were stimulated as indicated, washed in PBS, and lysed with Laemmli buffer. Samples were resolved by $10 \%$ SDS-PAGE and transferred by semidry transfer onto nitrocellulose. Blots were developed using the enhanced chemiluminescence detection method. Films were preflashed, exposed for suitable times to ensure exposures in the linear range, digitized by flatbed scanning, and quantified as above.

Immunostaining and morphological analysis of transfected cells. Immunocytochemical staining was performed as follows. Coverslips with neurons at 6-7 DIV or HeLa cells were fixed with $4 \%$ paraformaldehyde for $20 \mathrm{~min}$ followed by permeabilization in PBS/Triton X-100 (1\%) for $3 \mathrm{~min}$. After washing with PBS, cells were blocked with $10 \%$ serum $/ 0.2 \%$ Tween-20/ PBS. Incubation with primary antibodies was overnight at $4^{\circ} \mathrm{C}$ using 1:200 SAPK antiserum (generous gift of John M. Kyriakis, MGH), $2 \mu \mathrm{g} / \mathrm{ml}$ MKK4 (K-18), $2.5 \mu \mathrm{g} / \mathrm{ml}$ MKK7 (C-19), or $5 \mu \mathrm{g} / \mathrm{ml}$ p38 (C-20) (Santa 
Cruz Biotechnologies), or with 1:25 anti-phospho-JNK (New England Biolabs). Immunostaining for JIP1 was with 1:100 anti-JIP1 monoclonal (Yasuda et al., 1999). The specificity of SAPK staining was verified by preincubating anti-SAPK with $150 \mu \mathrm{g} / \mathrm{ml}$ recombinant GST-SAPK to neutralize specific staining. Incubation with primary antibodies was followed by incubation with 1:800 affinity-purified goat anti-rabbit or 1:80 rabbit anti-goat IgG biotin conjugates (Sigma) and 1:200 ExtrAvidin fluorescein conjugate (Sigma). JIP1 immunoreactivity was detected with 1:500 Alexa $488 \alpha$-mouse. Before mounting, nuclei were stained with 0.2 $\mu \mathrm{g} / \mathrm{ml}$ propidium iodide for JNK, phospho-JNK, p38, and MKK4, and with $0.02 \mu \mathrm{g} / \mathrm{ml}$ for MKK7. Slides were examined under FITC and TRITC wavelengths using a Leica confocal microscope (Heerbrugg, Switzerland) with a $100 \times$ objective, and a zoom of 2 . Multiple sections were scanned, and sections through nuclei are shown, with sections closer to the coverslip shown in insets. Cerebellar granule neurons transfected with pCMV- $\beta$ galactosidase for the morphological studies were fixed $48 \mathrm{hr}$ after transfection and stained as outlined above. Incubation overnight with primary antibody 1:2000 rabbit anti- $\beta$-galactosidase $\left(5^{\prime} \rightarrow 3^{\prime}\right.$ Inc., Boulder, CO) was followed by $1 \mathrm{hr}$ incubation with biotin-conjugated goat anti-rabbit IgG and then 1:500 streptavidin Alexa-488 (Molecular Probes, Leiden, The Netherlands). Nuclei were counterstained with Hoechst. Analysis of neurite number was performed within 1 week of immunostaining using a Leica DM IRB with $100 \times$ objective. This sensitive staining procedure was necessary to allow visualization of fine processes. No distinction was made between dendritic or axonal processes during the counting. A projection emanating directly from the cell body equal to or greater in length than one-half the cell body diameter was measured as a process. Additiona branching beyond the cell body was not counted. Accurate counting of processes required focusing in different planes of view, and thus the number of projections visible in one focal plane (as shown in Fig. $11 C$ ) does not reveal processes in higher and lower planes.

$R T-P C R$. Total RNA was isolated from cells cultured in 24-well plates with $300 \mu \mathrm{l}$ per well Tri-reagent (Sigma) according to the manufacturer's instructions. The RNA was heat-denatured $\left(5 \mathrm{~min}\right.$ at $\left.72^{\circ}\right)$ and poly $(\mathrm{A}+)$ RNA was reverse-transcribed in a $20 \mu \mathrm{l}$ reaction containing $200 \mathrm{U}$ Moloney murine leukemia virus (MMLV)-RT, $1 \times$ MMLV-RT buffer (Promega), 30 U RNase inhibitor $\left(5^{\prime} \rightarrow 3^{\prime}\right.$ Inc.), $1.25 \mathrm{~mm}$ dNTPs (Finnzymes, Espoo, Finland), and oligo-dT (Promega), and incubated for $90 \mathrm{~min}$ at $42^{\circ} \mathrm{C}$, and the reaction was terminated by incubating for $5 \mathrm{~min}$ at $95^{\circ} \mathrm{C}$. An aliquot of cDNA was used in a $20 \mu \mathrm{l}$ PCR reaction containing $1 \mathrm{U}$ Dynazyme, $1 \times$ Dynazyme buffer (Finnzymes), $1 \mu \mathrm{M}$ of each primer (Protein and Nucleic Acid Chemistry Laboratory, University of Leicester, Leicester, UK), and $250 \mu \mathrm{M}$ dNTPs (Finnzymes). Amplification was performed with the following primer sets: (1) $\beta$-actin: sense (2255-2274) 5'-TCC GGA GAC GGG GTC ACC CA-3' (Miller and Johnson, 1996), antisense (3111-3132) 5'-CTA GAA GCA TTT GCG GTG CAC G-3'; (2) c-jun: sense (1728-1747) 5'-GCT TCT CTA GTG CTC CGT AA-3' (Schafer et al., 1996), antisense (2483-2502) 5'-TCT AGG AGT CGT CAG AAT CC-3' (Schafer et al., 1996); (3) JIP: sense (1628-1648) 5'-TCG GCA TGA AGA TGA ACT TGA-3'; antisense (1929-1949) 5'-CTT GTT ATT CTT TGG ATG GTA-3'. These oligos are expected to recognize the following $J I P$ forms: mouse $J I P-1 a, J I P-2 b$, and $J I P-3$ (perfect match; rat sequences are not currently available for these), and rat $J I P-1 b$, $J I P-1 c$, and $J I P-2 a$ (only one base mismatch). The oligos do not correspond to the recently reported human JIP2 (Yasuda et al., 1999) and JIP3 (Kelkar et al., 2000), which probably represent additional families of JIPs. PCR parameters were as follows: $95^{\circ} \mathrm{C}, 1.5 \mathrm{~min} ; 50^{\circ} \mathrm{C}$ (for $c$-jun and $J I P$ ) or $58^{\circ} \mathrm{C}$ (for $\beta$-actin), $1.5 \mathrm{~min} ; 72^{\circ} \mathrm{C} 1.5 \mathrm{~min}$, for 25 ( $\beta$-actin) or 30 cycles $(c$-jun $)$. Aliquots of the PCR reactions were run on $1.5 \%$ agarose gels containing ethidium bromide. RT-PCR data shown are representative of three separate experiments. Reactions produced only a single band (two in the case of $J I P$ ) of the expected size, and PCR without template produced no detectable product.

\section{RESULTS}

\section{Constitutive JNK activity in cerebellar granule neurons exceeds that of anisomycin-stimulated kinase activity in U937 cells}

JNKs are strongly regulated by stresses and are believed to play an important role in neuronal apoptosis. Cerebellar granule neurons are a widely used model for the study of neuronal death mechanisms. Surprisingly, however, apoptotic stresses have been reported not to induce substantial JNK activation in cerebellar granule neurons (Kawasaki et al., 1997; Gunn-Moore and Tavare, 1998; Watson et al., 1998). It has been speculated that these cells have a high basal activity, possibly explaining the lack of JNK response to apoptotic stimuli (Kawasaki et al., 1997; Gunn-Moore and Tavare, 1998). Thus we assessed the level of basal activity of cerebellar granule neuron-derived JNK compared with JNK from the U937 macrophage line, a cell type in which $\mathrm{JNK}$ is well characterized (Dai et al., 1995).

Lysates containing equal protein from U937 cells and cerebellar

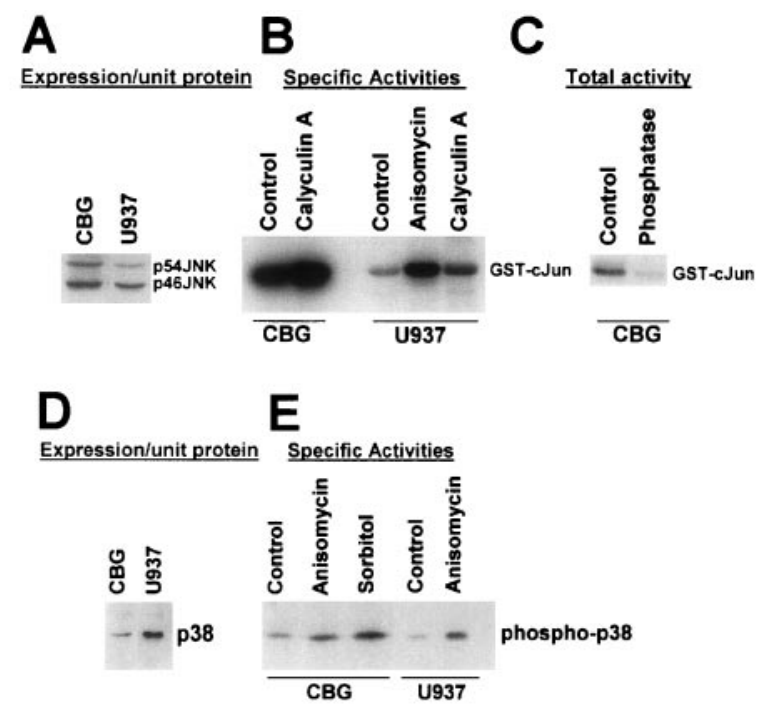

Figure 1. Cerebellar granule neuron-derived JNK activity is elevated above that of stressed U937 cells, whereas p38 activity from neurons is low and responds to stress. $A$, Equal amounts of protein $(25 \mu \mathrm{g})$ from 1 DIV cerebellar granule neuron $(C B G)$ or U937 cell extracts were electrophoresed and immunoblotted with anti-SAPK. JNK expression was on average 1.7-fold higher in CBG extracts. $B$, Kinase assay lysates were normalized for JNK expression, and specific JNK activity was measured by immunecomplex kinase assay. The specific activity of JNK from 1 DIV CBG extracts was higher than that in anisomycin-treated U937 cells. Treatments were with calyculin $\mathrm{A}(1 \mu \mathrm{M})$ for $30 \mathrm{~min}$ or anisomycin $(50 \mu \mathrm{g} / \mathrm{ml})$ for 45 min. After stimulation, JNK was isolated using polyclonal anti-SAPK, and immune-complex kinase assays were performed using GST-c-Jun(5-89) as substrate. $C$, Treatment of cerebellar granule neuron-derived JNK with alkaline phosphatase indicated that the basal activity measured was phosphorylation dependent. Representative images are shown, and quantitated data from four experiments are in Figure 2. D, p38 expression was compared in 1 DIV cerebellar granule neurons and U937 cells. Forty micrograms of CBG and U937 cell lysates were resolved by SDS-PAGE and immunoblotted using polyclonal anti-p38 $(n=4)$. U937 cells expressed on average sevenfold more p38 than cerebellar granule neurons. $E$, As in $B$, lysates were normalized for kinase expression, and specific activities of p38 from cerebellar granule neurons and U937 cells after treatment for $45 \mathrm{~min}$ with anisomycin $(50 \mu \mathrm{g} / \mathrm{ml})$ or sorbitol $(300 \mathrm{~mm})$ are shown. Treatment with anisomycin lead to a $399 \pm 59 \%$ increase in p38 activity in neurons, comparable with that in U937 cells of $302 \pm 80 \%$. Representative images from four separate experiments are shown $(A-E)$.

granule neurons were run on SDS-PAGE and immunoblotted with antiserum recognizing all JNK isoforms. JNK expression (54 and $46 \mathrm{kDa}$ bands) was higher in cerebellar granule neurons than in U937 cells (Fig. $1 A$ ); therefore, lysates from cerebellar granule neurons and U937 cells were normalized for this difference in JNK expression, and kinase assays were performed. The specific activity of cerebellar granule neuron JNK was eightfold greater than JNK from U937 cells (Fig. 1B). Anisomycin $(50 \mu \mathrm{g} / \mathrm{ml})$ induced an eightfold elevation in U937 cell JNK activity as reported previously in these cells (Kyriakis et al., 1994; Dai et al., 1995). General inhibition of phosphatases with excess calyculin A ( $1 \mu \mathrm{M})$ moderately increased JNK activity in both cell types. Interestingly, both the basal kinase activity and the calyculin A-induced activity in U937 cells were considerably lower than the basal activity in cerebellar granule neurons. Thus, even anisomycin-treated U937 cells expressed lower specific JNK activity than unstimulated cerebellar granule neurons.

Both threonine and tyrosine phosphorylation are required for activity of JNK (Kyriakis et al., 1995). Because the basal activity in cerebellar granule neurons was maintained by an unknown mechanism (Fig. $1 B$ ), we tested whether this activity was dependent on its phosphorylation state. Samples were treated with alkaline phosphatase, and kinase activity toward GST-c-Jun(5-89) was measured after thorough washing of immunoprecipitates in buffers containing phosphatase inhibitors (see Materials and Methods). Alkaline phosphatase treatment strongly reduced the basal activity 
of immunoprecipitated JNK (Fig. 1C), indicating that the high basal activity measured from these cells was dependent on phosphorylation of JNK.

\section{Neuronal p38 shows typical responses to cellular stresses}

Because the basal activity of neuronal JNK was elevated, we decided to assess the activation state of p38, another mitogenactivated protein kinase (MAPK) family member that is activated by stress (Kyriakis and Avruch, 1996). Expression levels of p38 were low in cerebellar granule neurons compared with the U937 cell line (Fig. 1D). As in Figure 1, lysates were normalized, this time for p38 expression, and anti-phospho-p38 immunoreactivity was used as an indicator of the relative activities of p38 from both cell types. Unlike neuronal JNK, p38 from neurons showed low basal specific activity, comparable with that from U937 cells. Treatment with anisomycin or osmotic shock for 45 min typically induces p38 activity in cell lines (Kyriakis and Avruch, 1996; Hazzalin et al., 1997), and p38 from neurons showed a classic stress response similar to that of U937 cells (Fig. $1 E$ ). The low basal p38 activity in these cells suggests that high JNK activity is not caused by stress imposed by cell preparation or maintenance in culture.

\section{Elevated JNK activity at 1 DIV is not mediated by glutamate receptor activity}

Neuronal JNK activity can be induced by extracellular glutamate (Schwarzschild et al., 1997; Mukherjee et al., 1999). To assess whether low levels of glutamate present in the culture medium (Aronica et al., 1993) were responsible for the elevated JNK activity observed at $1 \mathrm{DIV}$, cells were treated with glutamate receptor antagonists $\mathrm{MK} 801, \mathrm{CNQX}$, and $\mathrm{MCPG}$, specific for NMDA, AMPA/kainate, and metabotropic-type receptors, respectively. None of these treatments reduced basal JNK activity; indeed, inhibition of metabotropic receptors with MCPG caused a small but significant increase in JNK activity (Fig. 2). Furthermore, treatment of cells with the L-type $\mathrm{Ca}^{2+}$ channel antagonist nifedipine failed to reduce constitutively elevated JNK activity.

\section{Elevated specific JNK activity in cerebellar granule neurons is not reduced by removal of serum}

To investigate whether high neuronal JNK activity resulted from other components present in the culture medium, cerebellar granule neurons were either (1) deprived of serum for $24 \mathrm{hr}$ or (2) grown in the absence of elevated $\mathrm{KCl}$ (Fig. 2). Expression of JNK protein decreased after these treatments, but there was no decrease in specific JNK activity. No decrease in specific JNK activity was detected with shorter times of serum deprivation either (data not shown). Cerebellar granule neurons are commonly grown in culture medium containing elevated $\mathrm{KCl}(25 \mathrm{~mm})$. This is thought to mimic the innervation in vivo (Thangnipon et al., 1983) and protects mature neurons in culture from a late phase of cell death (Gallo et al., 1987; Courtney et al., 1997). To test whether the elevated JNK activity observed by 1 DIV (Fig. 1) resulted from the excitation induced by elevated $\mathrm{KCl}$, freshly isolated cerebellar granule neurons were plated in culture medium without supplementary KCl. Plating of cells in nondepolarizing medium caused no significant decrease in JNK activity and could not explain why this cell type had 8- to 10-fold higher activity than cell lines such as U937 cells, PC12 cells, and SH-SY5Y neuroblastoma cells (Figs. 1, 4)

\section{Cerebellar granule neuron JNK shows a moderate response to the protein synthesis inhibitor anisomycin, a strong activator of JNK in non-neuronal cells}

c-Jun kinases typically undergo 10 - to 20-fold activation when treated with inhibitors of protein synthesis (Kyriakis et al., 1994; Dai et al., 1995; Kyriakis et al., 1995; Iordanov et al., 1997). To test the responsiveness of neuronal JNK to these compounds, immunecomplex kinase assays were performed using GST-c-Jun(5-89) as substrate. Differentiating cerebellar granule neurons were stimulated with anisomycin $(50 \mu \mathrm{g} / \mathrm{ml}, 40 \mathrm{~min})$, an inhibitor of protein synthesis. This treatment induced a moderate, twofold increase in

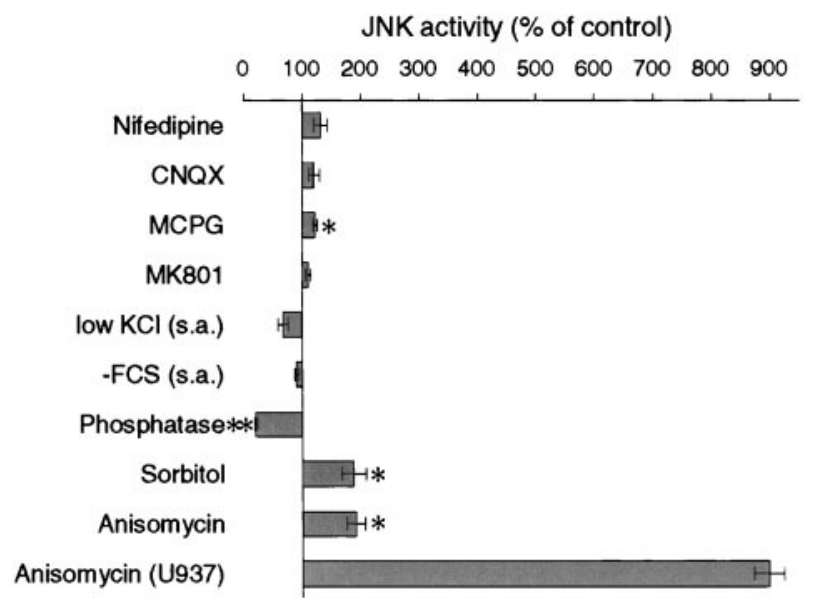

Figure 2. Glutamate receptor activity does not mediate elevated basal JNK activity. To determine whether glutamate receptor activity might contribute to basal JNK activity $(\sim 10$-fold elevated compared with cell lines), cerebellar granule neurons at $1 \mathrm{DIV}$ were treated for $1 \mathrm{hr}$ with $50 \mu \mathrm{M}$ CNQX, $25 \mu \mathrm{M}(R S)-\mathrm{MCPG}, 2 \mu \mathrm{M}(+)-\mathrm{MK} 801$, or $1 \mu \mathrm{M}$ nifedipine. JNK activity was assessed by phospho-JNK immunoblotting and normalized to control samples. These treatments did not reduce neuronal JNK activity; indeed, inhibition of mGluR-type receptors caused a small but significant increase in JNK activity. To investigate whether culture medium supplements might contribute to the basal JNK activity, the effects of serum depletion (-FCS) and low $\mathrm{KCl}$ were assessed by phospho-JNK immunoblotting. Total JNK activity was measured from 7 DIV CBG neurons grown for $24 \mathrm{hr}$ in the absence of FCS but with supplementary $\mathrm{KCl}(25 \mathrm{mM})$ to prevent neuronal death. Both activity and expression of CBG JNK decreased; thus specific activities (s.a.) for JNK are shown for these treatments. Serum depletion did not significantly alter specific JNK activity. To assess whether $\mathrm{KCl}$ might contribute to the high basal activity, we measured JNK activity from 1 DIV CBG neurons grown for $24 \mathrm{hr}$ in low $\mathrm{KCl}$ (5 mM). The activity was not significantly reduced. Quantitated data for JNK activation after treatment with classic JNK stimuli as described in Figure 1 are shown. Cerebellar granule neurons at 1 DIV were treated with anisomycin $(50 \mu \mathrm{g} / \mathrm{ml})$ or sorbitol $(300 \mathrm{mM})$ for $45 \mathrm{~min}$, or with alkaline phosphatase (see Materials and Methods); JNK activity was measured by immune-complex kinase assay. Normalized, mean data \pm SEM are shown. Significance levels as assessed by Student's $t$ test are indicated ( ${ }^{*} p<0.05$ and $* * p<0.001)$.

total JNK and MKK4 activity above basal levels (Figs. 2, 3). Treatment with anisomycin caused a reproducible retardation in the mobility of c-Jun, with complete loss of the fastest mobility band, consistent with c-Jun phosphorylation. This result was corroborated by increased immunoreactivity of c-Jun phosphoserine 63. A time course of JNK phosphorylation after treatment with 10 $\mu \mathrm{g} / \mathrm{ml}$ anisomycin (a concentration at which JNK activation is maximal) (Iordanov et al., 1997) showed that p46 JNK phosphorylation increased within minutes and remained elevated for up to 2 hr (Fig. 3B). The p54 JNK isoforms were also rapidly activated in response to anisomycin (data not shown). The response of neuronal JNK to osmotic stress, which typically activates JNK of nonneuronal cells 10 -fold, was also measured by immune-complex kinase assay. Treatment of cerebellar granule neurons with $0.3 \mathrm{~mm}$ sorbitol for 45 min also resulted in a twofold activation above basal levels. Quantitative data for these responses is in Figure 2.

\section{Contribution of JNK to elevated c-jun mRNA in response to anisomycin-induced stress in cerebellar granule neurons}

MEF2, a well known target of p38, regulates the c-Jun promoter (Han and Prywes, 1995; Coso et al., 1997; Han et al., 1997), and c-Jun can autoregulate its own promoter activity. Thus, it was feasible that c-Jun promoter activity might be regulated in response to activation of either p38 or JNK. Because c-Jun elevation is an important mediator of apoptotic signaling in these neurons (Watson et al., 1998), we tested whether $c$-jun levels were increased by p38 or JNK after cellular stress with anisomycin (Fig. 3C). Qualitative RT-PCR analysis using primers for $c$-jun showed an elevation of $c$-jun mRNA after $3 \mathrm{hr}$ treatment with $10 \mu \mathrm{g} / \mathrm{ml}$ 

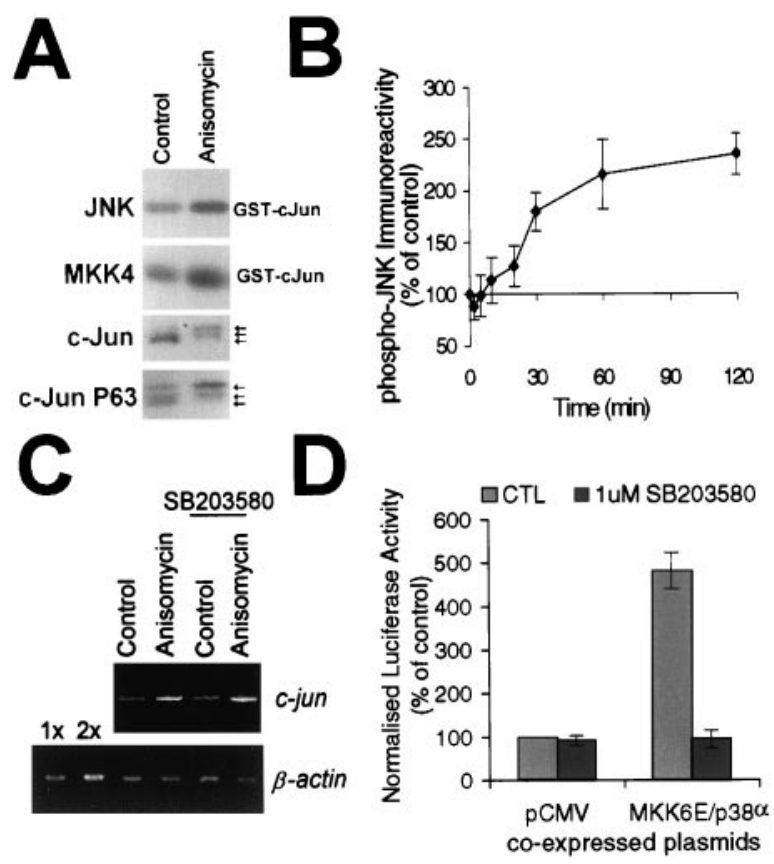

Figure 3. Anisomycin induces moderate activation of MKK4/JNK signaling and phosphorylation of c-Jun in cerebellar granule neurons. $A$, Cerebellar granule neurons at 1 DIV were stimulated with or without anisomycin $(50 \mu \mathrm{g} / \mathrm{ml})$ for $40 \mathrm{~min}$. JNK and MKK4 were immunoprecipitated from lysates, and immune-complex kinase assays were performed. Representative images from multiple experiments $(n \geq 4)$ are shown. Lysates of anisomycin-treated 1 DIV neurons were also blotted for c-Jun protein and Ser-63 phosphorylation. Although anisomycin only moderately activates JNK, there is a mobility shift with a dramatic loss of the most mobile form of c-Jun. $B$, A time course for anisomycin-induced $(10 \mu \mathrm{g} / \mathrm{ml}) \mathrm{p}-46 \mathrm{JNK}$ activation is shown (mean $\pm \mathrm{SEM}, n=3$ ). $C$, Qualitative RT-PCR analysis of $c$-jun mRNA from 5 DIV cerebellar granule neurons after treatment for $3 \mathrm{hr}$ with anisomycin $(10 \mu \mathrm{g} / \mathrm{ml}) \pm \mathrm{SB} 203580(1 \mu \mathrm{M})$. The anisomycininduced increase in $c$-jun mRNA is not eliminated by treatment with the p38 inhibitor, suggesting that $\mathrm{JNK}$ activation might contribute to the induction of $c$-jun. The bottom panel shows actin levels from parallel samples, indicating that the changes seen do not result from a general regulation of mRNA levels. Lanes 1 and 2 on this panel show reactions with equal $(1 \times)$ or twice $(2 \times)$ the amount of input cDNA as in other samples, indicating that the reactions were not saturating. $D$, SB203580 $(1 \mu \mathrm{M})$ blocks p38 $\alpha$ activity in these cells as detected by MEF2A-GAL4 induction of a GAL4-driven luciferase reporter. Quantitated data are shown (mean \pm SEM).

anisomycin. Cotreatment of cells with $1 \mu \mathrm{M}$ of the p38 $\alpha$ and $\beta$ inhibitor SB203580 ( $\mathrm{IC}_{50}$ values of 0.3 and $0.6 \mu \mathrm{M}$, respectively) ( $\mathrm{Li}$ et al., 1996; Kumar et al., 1997) did not eliminate the $c$-jun elevation (Fig. $3 C$ ), although the drug blocked p38 $\alpha$ activity (Fig. 3D). A broader spectrum inhibitor that blocks p38 $\alpha,-\beta$, and $-\gamma$, SB202190 $(3 \mu \mathrm{M})$, also failed to block the $c$-jun elevation, even when including a $1 \mathrm{hr}$ preincubation (data not shown), and p38 $\delta$ is reported not to be expressed in brain (Jiang et al., 1997) or to activate the cJun promoter (Marinissen et al., 1999). Thus, p38 activity alone cannot explain the $c$-jun induction in response to anisomycin, suggesting that JNK signaling might contribute (Fig. $3 A$ ).

\section{Activity of JNK from brain extracts and primary neurons in culture exceeds that of the SH-SY5Y neuroblastoma and the PC12 neuronal cell model}

The previous figures showed that both the specific and the total activity of JNK in cultured cerebellar neurons were higher than in U937 cells. To investigate whether this high activity was a general property of neuronal systems, we determined the specific activity of JNK from snap-frozen tissue samples, primary cultured neurons, and neuronal-like cell lines. Developmental changes in brain tissues and primary neuronal cultures were assessed by taking samples at different developmental stages by a method demonstrated to retain JNK responsiveness in tissues (see Materials and Methods). Equal protein was loaded onto gels, and $\mathrm{JNK}$ was detected by
A

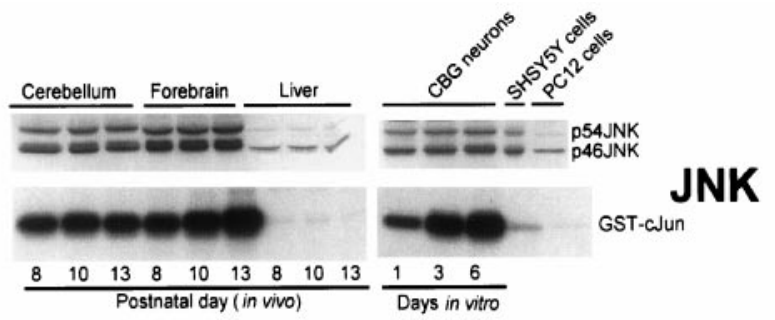

B

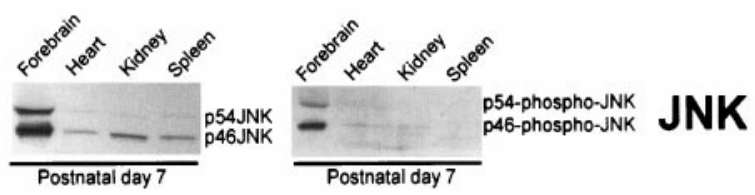

C

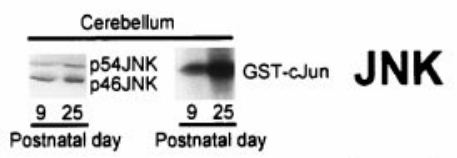

D

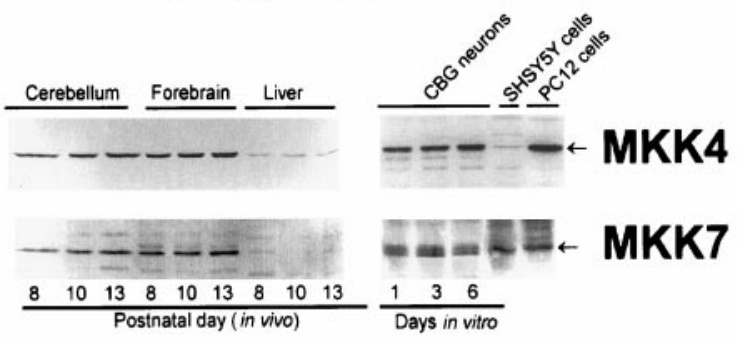

E

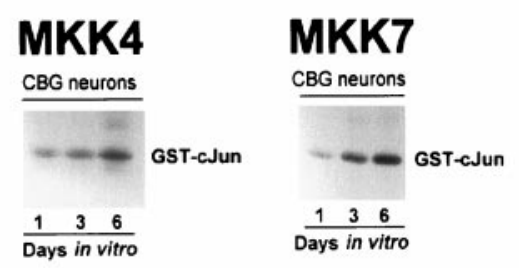

Figure 4. Specific activities of JNK and JNK kinases from brain tissues and primary neurons are elevated compared with those from SH-SY5Y and PC12 cells. $A$, Rat brain tissues and cerebellar granule neurons ( $C B G$ neurons) were compared with non-neural tissue and neuron-like cell lines, SH-SY5Y and PC12 cells, for both JNK expression and specific activity. Top panel, Equal protein $(25 \mu \mathrm{g} / \mathrm{lane})$ from tissues and cell lysates was loaded and immunoblotted using anti-SAPK. Elevated levels of JNK protein are seen in brain tissues and primary neurons. The neuroblastoma cells also show elevated JNK expression compared with PC12 cells. Bottom panel, Lysates for kinase assays were normalized for JNK expression, and immune-complex kinase assays were performed. Although JNK levels were normalized between samples, JNK activities from brain tissues and primary neurons are still considerably higher than from liver, SH-SY5Y, and PC12 cells. Data shown for tissue samples and cells are representative of two and four repeats, respectively. $B$, Specific JNK expression and activity from forebrain was compared with other tissues as described in $A$ except that activities were this time measured with phosphospecific JNK antibodies. Again, neural-derived JNK activity is elevated above that of JNK from non-neuronal tissues. Data shown are representative of tissues from three separate animals. $C$, Specific expression and activity of JNK from rat cerebellum of postnatal days 9 and 25 are shown. Normalization of samples was performed exactly as described in $A$. The specific activity of cerebellar JNK increases during this time. Data shown represent results from three experiments. $D$, The same procedure as described in $A$ was used to compare MKK4 and MKK7 expression in brain tissues and CBG neurons to cell lines. Expression of both MKK4 and MKK7 is high in brain. In primary cultured neurons and cell lines, levels of MKK4 and MKK7 are similar, with the exception of MKK4 in neuroblastoma cells. Data from tissues and cells are representative of two and four separate experiments, respectively. $E$, Representative images from two-step immune-complex kinase assays showing the developmental regulation of MKK4 and MKK7 activities in cerebellar granule neurons are shown. Representative images of four and three repeats are shown, respectively. Quantitated data are shown in Figure 5. 


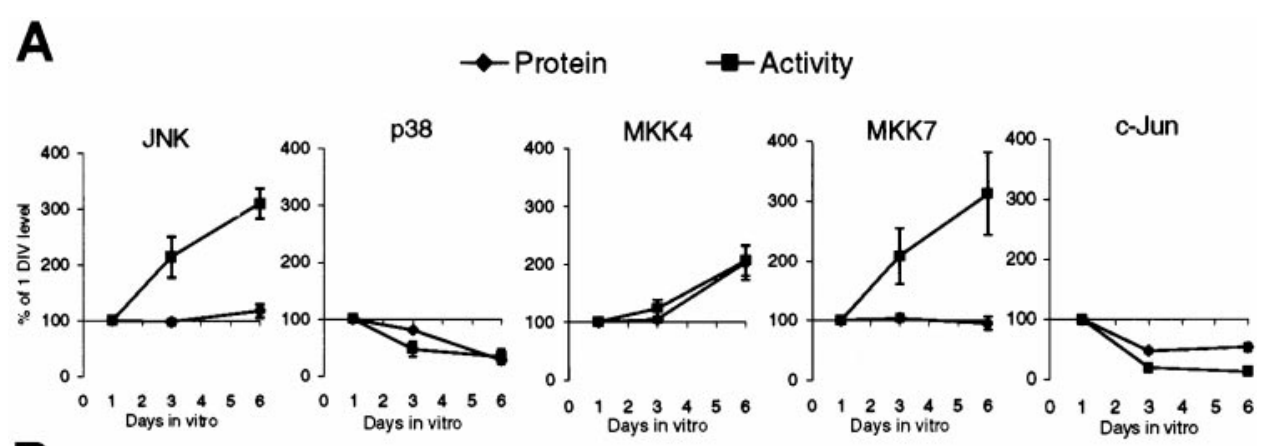

B
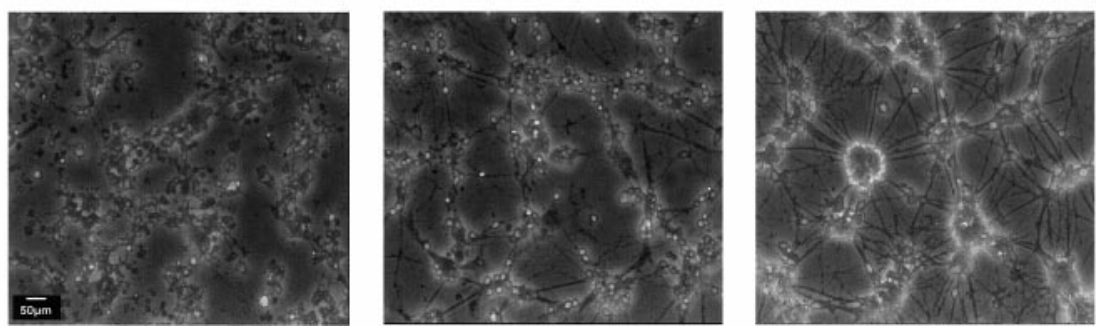

Figure 5. JNK and MKK7 specific activities increase, whereas expression and activity of c-Jun decrease during maturation of cerebellar granule neurons. A, Lysates from differentiating cerebellar granule neurons in culture were loaded according to cell number and immunoblotted for JNK, p38, MKK4, MKK7, and c-Jun expression ( $)$ or total phospho-JNK, phospho-p38, or p63-c-Jun immunoreactivity, or MKK4 and MKK7 immune-complex kinase activities were measured (ם). Quantitated data from multiple experiments (mean $\pm \mathrm{SEM}, n \geq 3$ ) are shown. Error bars are shown for each data point; SEMs smaller than the symbols are not visible. Although JNK and MKK7 expression are not significantly upregulated during differentiation, their activities rise sharply. Levels of c-Jun, p38, and c-Jun serine 63 phosphorylation, and activation of $\mathrm{p} 38$, all decrease as cells mature in vitro. $B$, Brightfield images of cerebellar granule neurons differentiating in culture. By 6 DIV, a dense network of processes has formed. immunoblotting. The relative expression of JNK protein (per unit total protein) from cerebellar and forebrain extracts was high compared with liver (Fig. 4A, top panel). Samples were normalized for this difference in JNK expression, and equal amounts of JNK were used for kinase assays. It is clear that brain-derived JNK also showed a high specific activity (activity per unit JNK), whereas JNK from liver showed little or no basal activity (Fig. $4 A$, bottom panel). Although we cannot exclude a contribution from glial cells to the high JNK activity in brain, immunofluorescent studies failed to detect JNK activity in glia (data not shown). When cultured cells were compared, similar expression levels of JNK protein were found in primary cultured cerebellar granule (CBG) neurons and the SH-SY5Y neuroblastoma line (Fig. 4A, top panel). However, the specific activity of JNK from primary cerebellar granule neurons was clearly elevated compared with that measured in cell lines (Fig. 4A, bottom panel). Both expression and activity of PC12 cell JNK were more similar to those of liver than brain, neurons, and neuroblastomas. The levels of JNK expression (JNK per unit protein) were not developmentally regulated from postnatal day 8-13 (Fig. 4A); however, there was a clear increase in the specific activity of JNK (activity per unit JNK) during development of forebrain and the primary neuronal culture. As with liver, JNK expression from heart, kidney, and spleen was relatively low (Fig. $4 B$, left panel). When JNK levels were normalized between samples, the specific JNK activity was clearly lower in non-neural tissues (Fig. 4B, right panel).

\section{JNK activity from cerebellum and forebrain is developmentally upregulated}

The specific activity of JNK from forebrain increased from postnatal day 8 to 13 , whereas there was no clear upregulation of cerebellar JNK activity during this period (Fig. 4A). Because the cerebellum shows retarded maturation compared with forebrain, we tested whether an upregulation of JNK activity occurred at a later stage in the cerebellum (Fig. 4C). Interestingly, there was an increase in specific activity of JNK from cerebella of postnatal day 25 compared with postnatal day 9.

\section{JNK kinases MKK4 and MKK7 show high expression and activity in brain extracts and neurons}

JNK is activated by two known upstream kinases, MKK4 (also known as SEK1, JNKK1, or SAPKK1) and MKK7 (also known as JNKK2 or SAPKK4), dual specificity kinases that phosphorylate the JNK "TPY" motif and are themselves activated by phosphorylation. We investigated the expression of MKK4 and MKK7 from neural tissues, neurons in culture, and neuron-like cell lines. Both
MKK4 and MKK7 showed high expression in brain tissues compared with liver; however, in the neuronal and neuron-like cultured cells tested, levels of MKK4 and MKK7 expression were comparable, with the exception of MKK4, which was very low in neuroblastoma cells (Fig. 4D).

To investigate the developmental upregulation of MKK4 and MKK7 activity, immune-complex kinase assays of MKK4 and MKK7 isolated from cells at 1,3, and 6 DIV were performed (Fig. $4 E$ ). This showed that total activities of both of these JNK kinases increased during the neuronal differentiation. Quantitated data are shown in Figure $5 A$.

\section{Specific activities of MKK7/JNK increase during differentiation of cerebellar granule neurons, whereas c-Jun activity decreases $\mathbf{5}$}

Cerebellar granule neuron JNK activity was highly elevated $24 \mathrm{hr}$ after plating as shown in Figures 1 and 4. We assessed whether high basal activity resulted from isolation-associated stress by measuring activities of JNK, MKK4, and MKK7 at 1, 3, and 6 DIV (Figs. 4, $5 A$ ). During this period, neurons mature and form a dense network of processes (Fig. $5 B$ ). Perhaps surprisingly, instead of a decline in JNK activity after isolation and plating of neurons, total activities of JNK, MKK4, and MKK7 increased as neuronal differentiation progressed. Because expression of many proteins increases during differentiation of these neurons (Coffey et al., 1997), increased protein expression could account for the regulation of $\mathrm{JNK}$, MKK4, and MKK7 activities measured. Although we found that MKK4 expression increased in parallel to its activity from 3 to 6 DIV, there was no increase in JNK and MKK7 expression during this time (Fig. $5 A$ ). Thus a specific upregulation of MKK $7 / \mathrm{JNK}$ signaling occurred during the development of these neurons in culture. Conversely, both expression and specific activity of p38 decreased during development of these cells as did the expression and phosphorylation of the nuclear JNK target, c-Jun (Fig. 5A).

\section{Induction of JNK activity in maturing neurons is not dependent on elevated $\mathrm{KCl}$}

Cerebellar granule neurons are typically grown in elevated potassium, resulting in elevated cytoplasmic calcium levels (Courtney et al., 1990). This has been shown to facilitate their survival beyond 6 DIV (Thangnipon et al., 1983). Although culturing of these cells in low $\mathrm{KCl}(5 \mathrm{~mm})$ does not affect survival during the first 6 DIV (Courtney et al., 1997), some intracellular signaling responses are altered during this period by culturing in low $\mathrm{KCl}$ (Courtney et al., 1997). Thus, we assessed whether the maturation-associated increase in JNK activity depended on elevated $\mathrm{KCl}(25 \mathrm{~mm})$. As in 
Figures 1 and 4, lysates from CBG neurons cultured in high or low $\mathrm{KCl}$ were normalized for JNK expression, and specific JNK activities were measured using phosphospecific JNK antibodies (Fig. $6 A$ ). The increase in specific JNK activity was retained under these conditions of low $\mathrm{KCl}$ (Fig. 6B).

\section{Bulk JNK activity resides in the cytoplasmic fraction in resting cells}

We have established that cerebellar granule neuron JNK activity was highly elevated (Fig. 1) and that MKK7/JNK activities were upregulated as these neurons differentiated (Fig. 5), suggesting they may play a developmental role. To ascertain whether elevated JNK and MKK activities were involved in nuclear or cytoplasmic signaling, fractionation studies and immunofluorescent analysis were performed to assess the subcellular localization of endogenous kinase expression and activity in mature (6-7 DIV) neurons (Figs. 7, 8).

Amounts of cytosolic and nuclear fractions of mature (6-7 DIV) cerebellar granule neurons corresponding to equal numbers of cytosols and nuclei were loaded onto gels and immunoblotted for JNK, MKK4, and MKK7 (Fig. 7A). The distribution of active JNK was assessed by normalizing cytosolic and nuclear fractions for JNK expression and immunoblotting with phospho-JNK (Fig. $7 A$, panel labeled $P-J N K)$. This normalization for JNK expression was necessary, because nuclear expression of JNK was otherwise too low to directly compare phospho-JNK immunoreactivity in cytosolic and nuclear fractions. The specific activity of cytosolic JNK was sevenfold higher than JNK from the nuclear fractions (Fig. $7 A, B$ ). Blotting of the same fractions for nuclear and cytosolic proteins c-Jun and $\mathrm{I} \kappa-\mathrm{B}$, respectively, was performed to demonstrate fraction purity (Fig. $7 A$ ). Cumulative data from three experiments are shown in Figure $7 B$. Not only is most of the JNK protein in the cytoplasm in these cells, but the bulk of the total JNK activity $(>95 \%)$ also resides outside the nucleus. Our ability to successfully isolate the small nuclear pool of JNK activity from cells that contain a much larger cytosolic activity was confirmed by the dramatically different specific JNK activities retained in the two fractions (Fig. 7B, PJNK).

\section{Cerebellar granule neurons differentiating in culture express all three JNK isoforms}

To identify which JNK isoforms were expressed in differentiating cerebellar granule neurons, fractions were immunoblotted with
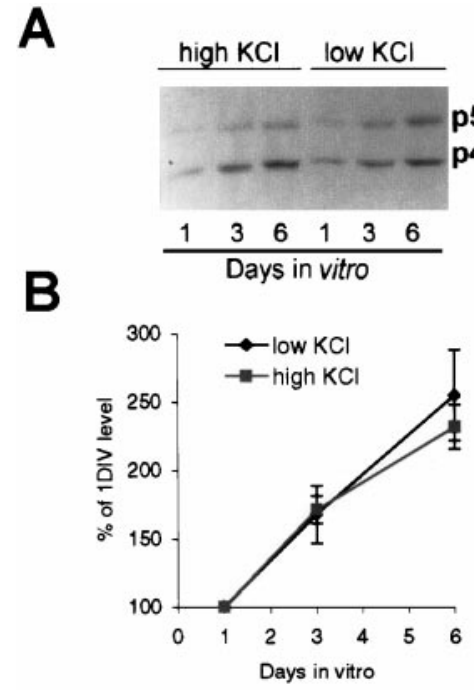

Figure 6. Developmental upregulation of CBG JNK activity occurs in cells grown with or without elevated $\mathrm{KCl}$. $A$, Specific JNK activities from differentiating cerebellar granule neurons grown in high $(25 \mathrm{mM})$ or low $(5 \mathrm{~mm}) \mathrm{KCl}$ were measured as described in Figure $4 B$. Lysates were normalized for expression of JNK, and kinase activity was assessed using phosphospecific JNK. $B$, Quantitated data, means \pm SEM from four separate experiments, are shown. antibodies selective for JNK1, JNK1 and -2, and JNK3 and -1, respectively (Fig. $7 C$ ). The predominant JNK1 isoforms expressed were in the $46 \mathrm{kDa}$ molecular weight range, whereas the antibody recognizing both JNK1 and JNK2 isoforms detected a $54 \mathrm{kDa}$ immunoreactive band, indicating that JNK2 isoforms were also expressed. Similarly, a $54 \mathrm{kDa}$ JNK3/1-specific immunoreactive band suggests the presence of the JNK3 isoform in these cells.

\section{Neuronal JNK and MKK4 are localized to both processes and cell bodies; MKK7 resides exclusively in the nucleus}

Cerebellar granule neurons are small, their cell bodies having diameters of $\sim 5-8 \mu \mathrm{m}$. The cell soma consists mainly of nucleus, with very little cytoplasmic space. Thus, we used confocal microscopy with a $100 \times$ objective to assess the subcellular distribution of endogenous stress-activated protein kinases. The antibodies that were used detect virtually no nonspecific bands (Fig. 7D), and a range of dilutions of antibodies were tested to avoid nonspecific staining. In addition, anti-SAPK was preadsorbed with recombinant SAPK, and dilutions that did not produce background staining were used (data not shown). Nonspecific nuclear staining with the SAPK and MKK4 antibodies was avoided by use of high dilutions of these antibodies. Representative micrographs of confocal sections through nuclei indicated primarily cytoplasmic staining for the MAPKs JNK and p38 (Fig. 8), with typical crescentshaped perinuclear staining in cell bodies (occasionally obscured by high staining in neurite bundles). This perinuclear localization was the most predominant feature of p38 staining in these neurons. The confocal scans exaggerate the nuclear distribution somewhat, because much of the dense network of neuronal processes is below the plane of scans through the nucleus. Staining in neuritic processes was most clearly seen in confocal sections closer to the $z$-plane of the coverslip (Fig. 8, insets). Thus, in the case of JNK and p38, intense staining of processes was seen in scans closer to the coverslip. JNK showed low level nuclear staining with more intense staining in neurites. JNK staining at 1 DIV showed a similar

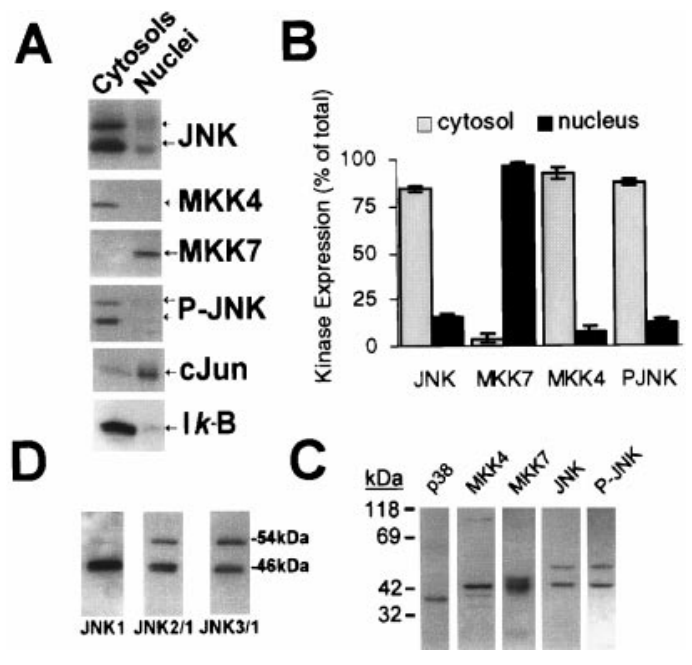

Figure 7. JNK activity is predominantly extranuclear in cerebellar granule neurons in culture. $A$, Cytosolic and nuclear fractions of cerebellar granule neurons at 7 DIV were analyzed for expression of JNK and JNK kinases MKK4 and MKK7. Cultures were lysed, cytosolic and nuclear extracts were separated, and amounts corresponding to $\sim 75,000$ cytosols and nuclei were loaded on gels, and expression levels were analyzed. Nuclear and cytosolic fractions were then normalized for JNK expression, and specific phospho-JNK immunoreactivity was measured $(P-J N K)$. Nuclear and cytosolic fractions were also blotted for c-Jun and I $\kappa$-B to validate the fractionation procedure. $B$, Quantitated data (mean \pm SEM, $n=3$ ) are shown. $C$, Lysates from cerebellar granule neurons at 6 DIV were immunoblotted with isoform-specific antibodies detecting JNK1, JNK2/1, and $\mathrm{JNK} 3 / 1$, respectively. All three JNK isoforms are expressed in cerebellar granule neurons in culture. $D$, Western blots of $C B G$ lysates show the relative specificity of the MAPK and MAPKK antibodies used in the immunofluorescent analysis (Fig. 8). 

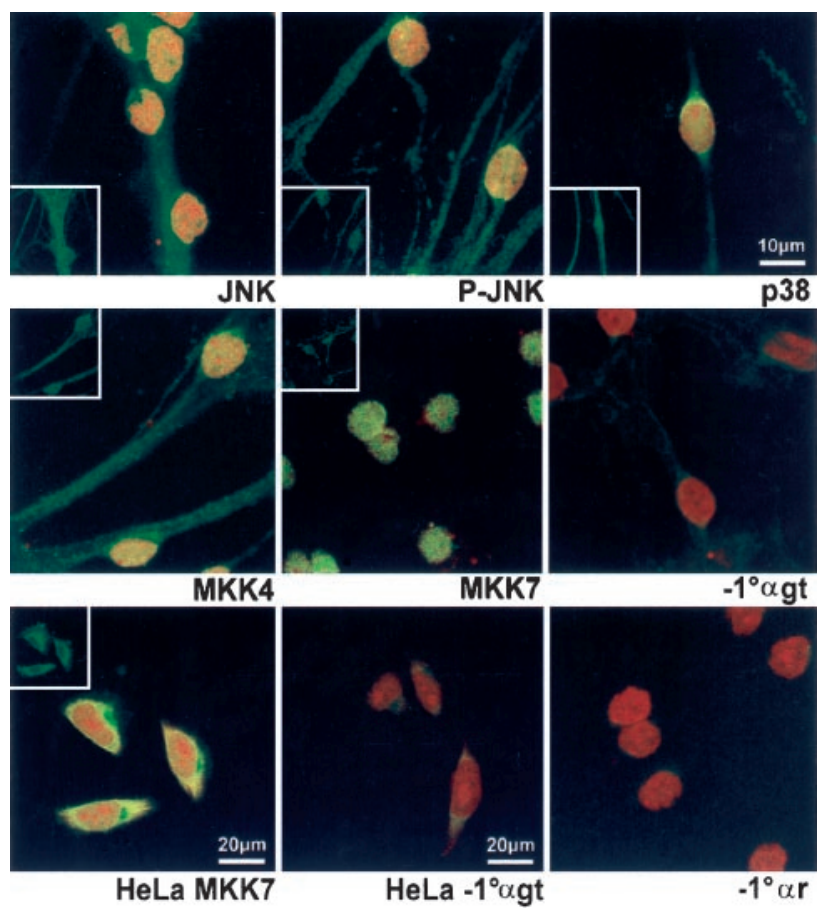

Figure 8. JNK/MKK4 are cytosolic, whereas MKK7 is exclusively nuclear in cerebellar granule neurons. Immunofluorescent microscopy was used to investigate the subcellular localization of endogenous $\mathrm{JNK}$ and JNK kinases in cerebellar granule neurons in vitro. Shown are confocal scans of immunofluorescent staining for JNK, P-JNK, MKK4, MKK7, and p38 in cerebellar granule neurons at 6-7 DIV (green). Nuclei were counterstained with propidium iodide (red). Overlapping staining appears yellow. Sections through the nuclei are shown with insets of scans closer to the coverslip that highlights staining in neuritic processes. Neuronal staining in the absence of primary antibodies, using biotin-conjugated anti-rabbit $\left(-1^{\circ} \alpha r\right)$ and anti-goat $\left(-1^{\circ} \alpha g t\right)$ is shown. All panels are scaled according to the scale bar depicted in the p38 panel except for the HeLa staining, which has its own scale. For comparison, endogenous MKK7 immunoreactivity in HeLa cells is shown. Propidium iodide gives relatively higher background cytoplasmic staining in HeLa cells, resulting in some yellow showing in HeLa cytoplasm. Staining in HeLa cells in the absence of $1^{\circ}$ antibody is also shown $\left(\mathrm{HeLa}-1^{\circ} \alpha g t\right)$.

distribution, with intense staining in the perinuclear region and processes. To assess the location of active JNK in neurons, cells were stained for phospho-JNK immunoreactivity. Phospho-JNK staining localized to processes and cell bodies, with slight staining in nuclei. Staining for MKK4 was typically punctate in the processes and the cell body, again with slight nuclear staining. Conversely, MKK7 immunoreactivity was localized almost exclusively to the nucleus. This distinct localization of MKK7 in the neurons contrasts sharply with its localization in HeLa cells (Fig. 8), a standard cell line often used for localization studies.

\section{Nuclear levels of JNK and MKK4 increase after anisomycin-induced stress}

The subcellular localization of high, specific JNK activity to the cytoplasm suggested a non-nuclear role for the elevated JNK activity that increased further during differentiation. This diverges from the classic stress-activated JNK response described in cell lines, which results in activation and translocation of JNK to the nucleus where it phosphorylates substrates such as c-Jun and ATF2 (Cavigelli et al., 1995). Although we detected a small JNK activation by stress (40 min anisomycin) at $1 \mathrm{DIV}$ [percentage of control $192 \pm 16$ (Fig. 2)], the fold activation falls during differentiation (percentage of control $137 \pm 9$ at 7 DIV), possibly because the stress-induced JNK activation becomes progressively masked by the distinct, developmentally regulated JNK activity. To examine whether a small pool of neuronal JNK in these more mature neurons behaves like JNK in cell lines, we investigated whether stress induced nuclear translocation and whether it increased nu-
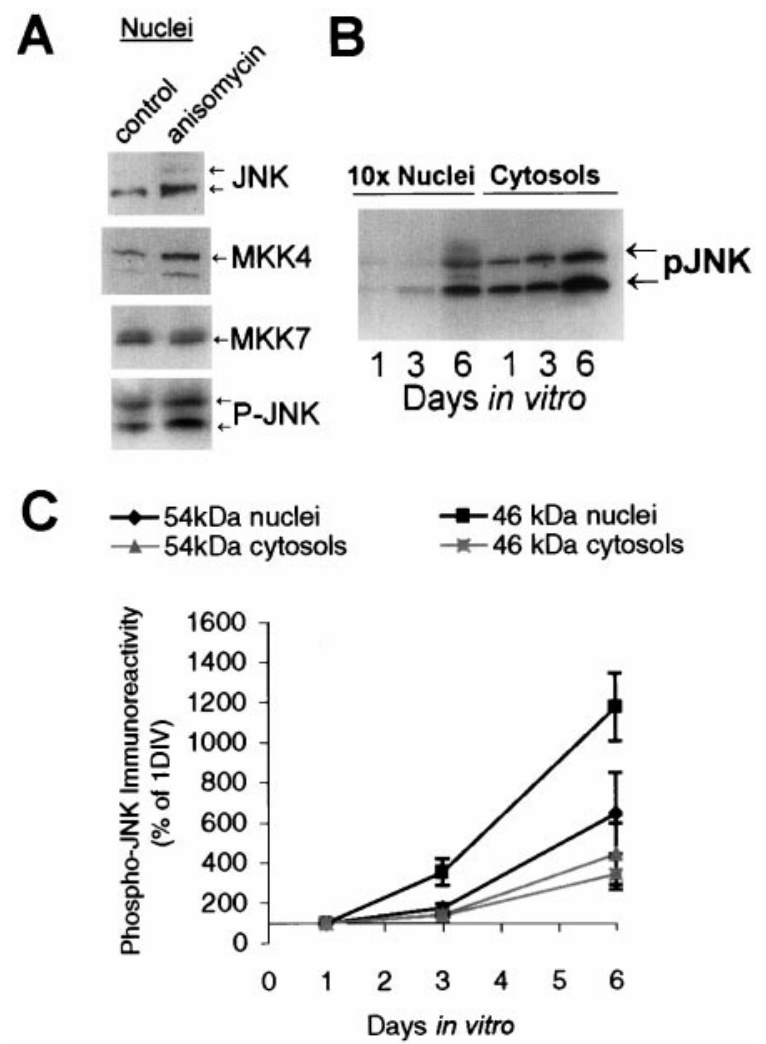

Figure 9. Translocation of nuclear JNK occurs after stress and during maturation of cerebellar granule neurons. $A$, Nuclear levels of JNK, MKK4, MKK7, and P-JNK after treatment with anisomycin were assessed by immunoblotting of nuclear fractions from 6 DIV cerebellar granule neurons treated \pm anisomycin $(50 \mu \mathrm{g} / \mathrm{ml})$ for $40 \mathrm{~min}$. Levels of JNK, phospho-JNK, and MKK4 increase twofold in nuclear fractions after stress, consistent with activation and nuclear translocation of these kinases. $B$, The developmental increase in JNK activity occurs in both cytoplasmic and nuclear compartments. Nuclear and cytoplasmic fractions were prepared from CBG neurons at 1,3 , and 6 DIV and immunoblotted for phospho-JNK. To enable a direct comparison of nuclear and cytoplasmic fractions to be made, 10 -fold more nuclei than cytoplasms were loaded (fraction of total). $C$, Quantitated data (mean $\pm \mathrm{SEM}, n=3$ ) for multiple experiments as outlined in $B$.

clear activity of JNK. Upstream kinases were also investigated (Fig. 9A). In addition to the increase in nuclear JNK activity, we found a clear nuclear translocation of JNK and MKK4 after 40 min stimulation with $50 \mu \mathrm{g} / \mathrm{ml}$ anisomycin, consistent with the classic JNK stress response of non-neuronal cells.

To assess the subcellular localization of the developmentally regulated $\mathrm{JNK}$, we isolated nuclear and cytoplasmic fractions from cells at 1,3, and 6 DIV and measured JNK activity (Fig. 9B). The larger cytoplasmic pool of JNK activity increased 3.5 -fold by 6 DIV, whereas the nuclear pool activities increased by 10 -fold (total phospho-JNK immunoreactivity of 46 and $54 \mathrm{kDa}$ bands) (Fig. $9 C)$. Because there was no upregulation in JNK protein levels in the nuclear compartment or in total cell lysates from 3-6 DIV (data not shown), these increases represent specific inductions of JNK activity in both pools. Once again, the reliability of the nuclear-cytoplasmic fractionation is confirmed by the dramatically different development curves of P-JNK immunoreactivity despite the much larger levels of P-JNK in the cytoplasm.

\section{Cerebellar granule neurons express the long form of JIP mRNA and protein}

On the basis of the data in Figure 8 showing MKK7 localization in the nucleus, we investigated the expression and location of the JNK/MKK7 scaffold protein JIP (Dickens et al., 1997; Whitmarsh et al., 1998; Yasuda et al., 1999). JIP isoforms contain putative nuclear localization and DNA binding sequences, the latter of 


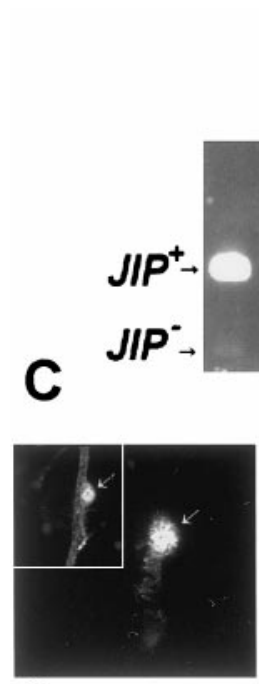

JIP
B
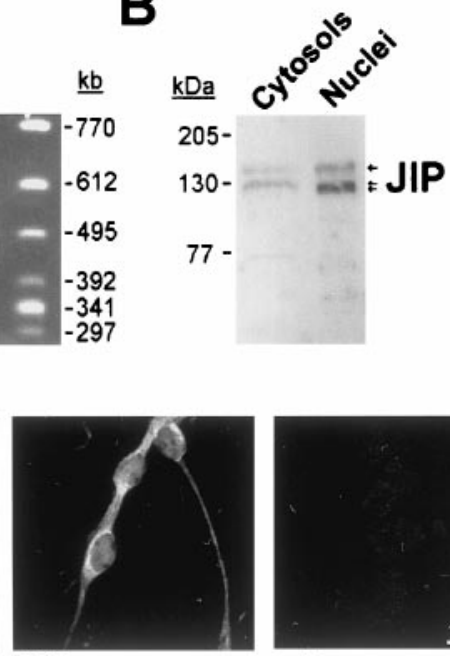

JNK

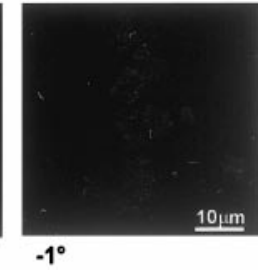

Figure 10. JIP is expressed in nuclear fractions from cerebellar granule cells. $A$, JIP mRNA was detected in 9 DIV cell extracts by RT-PCR with oligos complementary to both JIP-1a and JIP- $1 \mathrm{~b} / 1 \mathrm{c} / 2 / 3$, expected to produce fragments of size $324\left(J I P^{-}\right)$and $465\left(J I P^{+}\right)$, respectively. B, Equal proportions of cytosolic and nuclear fractions from 6 DIV CBG neurons were loaded and immunoblotted with monoclonal anti-JIP-1. JIP expression was predominantly nuclear, although lower levels of JIP were detected in cytosolic fractions. $C$, Confocal sections through nuclei of 6 DIV CBG neurons stained for JIP-1 and the corresponding $-1^{\circ}$ sample are shown; JNK staining is also shown for comparison. The inset shows a section closer to the coverslip.

which is absent in the shorter JIP-1a splice variant (Kim et al., 1999; Mooser et al., 1999; Yasuda et al., 1999). Semiquantitative RT-PCR showed that JIP mRNA was expressed in cerebellar granule neurons (Fig. 10 $A$ ), the predominant message being for the full-length JIP isoform. Antibody raised against JIP-1 detected two bands that were preferentially localized to the nuclear fraction (Fig. $10 B$ ). The predominant form ran at $120 \mathrm{kDa}$, the molecular weight on SDS-PAGE of JIP-1b [also known as IB1 (Bonny et al., 1998)], which possesses the putative DNA binding domain. Immunofluorescence analysis of JIP-1 in 6 DIV CBG neurons showed that JIP-1 was concentrated in nuclei, the location of MKK7. There is lighter punctate staining in the cytoplasmic compartment (Fig. $10 \mathrm{C}$ ) and also staining in growth cone-like structures (data not shown). The later is consistent with a recent report (Meyer et al., 1999). It may be that the predominant localization to the nucleus of JIP, which binds MKK7 and not MKK4 (Whitmarsh et al., 1998), tethers MKK7 to the nuclear compartment in CBG neurons.

\section{Inhibition of neuronal JNK activity leads to increased neurite number, indicating a regulatory role for JNK during neurite outgrowth}

In the PC12 cell neuronal model, JNK activity increases during neurite outgrowth induced by staurosporine (Yao et al., 1997), NGF (Eilers et al., 1998), or protease inhibition (Giasson et al., 1999), consistent with a role for JNK during neuronal differentiation. Our observation of developmentally regulated JNK activity in cerebellar granule neurons (Figs. 4, 5, 9) supports such a hypothesis. To test this, we used dominant inhibitory mutants to the JNK cascade, SEK1KR (Sanchez et al., 1994) and JIP-JBD [JIP-JNK binding domain (Dickens et al., 1997)], and assessed the effects on neurite outgrowth (Fig. 11). The efficiency of these mutants at blocking JNK activity was assessed by cotransfecting cerebellar granule neurons with JNK1 $\alpha 1$ together with SEK1KR or JIP-JBD after which immunopurified recombinant JNK1 $\alpha 1$ activity was measured. Coexpression of either SEK1KR or JIP-JBD blocked high basal JNK $1 \alpha 1$ activity, JIP-JBD being a more effective inhibitor (Fig. 11A). The effect of inhibition of JNK activity on neuritic architecture was measured by counting processes from neurons
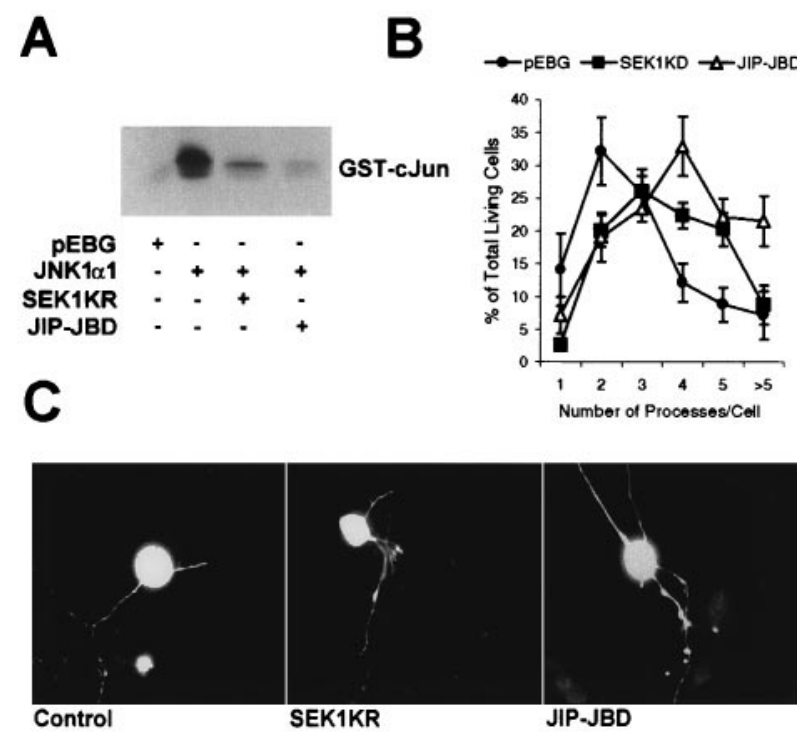

Figure 11. Inhibition of neuronal JNK activity results in increased projections from the cell body. $A$, Five days in vitro cerebellar granule neurons were transfected with pEBG-JNK1 $\alpha 1$, pEBG-SEK1KR, or pcDNA3-JIPJBD as shown, and $24 \mathrm{hr}$ after expression, JNK1 $\alpha 1$ was isolated on GSH beads and its activity was measured. Recombinant JNK $1 \alpha 1$ activity is elevated in unstimulated neurons, thus mimicking endogenous JNK activity. Coexpression of dominant inhibitory kinases SEK1KR or JIP-JBD effectively blocks JNK $1 \alpha 1$ activity. $B$, Three days in vitro cerebellar granule neurons were transfected as above with the addition of a $\beta$-galactosidase transfection marker. Forty-eight hours after transfection, cells were stained for $\beta$-galactosidase expression, and the number of processes emerging from living cells with lengths more than or equal to the cell body radius were counted. The percentage of cells with a given number of processes (1-5 or $>5$ ) were calculated for randomly chosen fields from five to six coverslips per condition. The number of cells counted under each condition was 233 for $\mathrm{pEBG}(n=5), 285$ for SEK1KR $(n=5)$, and 305 for JIP-JBD $(n=6)$ Data are expressed as means \pm SEM. $C$, A representative image from cells transfected as in $A$ and $B$ above is shown.

cotransfected with $\beta$-galactosidase, a marker for transfected cells that is expressed in the cytoplasmic compartment and efficiently highlights neuritic morphology. $\beta$-Galactosidase expression was monitored using a high-sensitivity staining procedure (see Materials and Methods) that allows visualization of fine processes, and cells were examined using a $100 \times$ objective. Cells with projections at least one cell body radius in length were counted; thus the number of projections and not process length was examined. Counterstaining with Hoechst was used to measure cell viability. Dead cells, apparent by their shrunken nuclei, were not included in the quantified data shown. There was no significant difference in viability of cells expressing pEBG empty vector, SEK1KR, or JIPJBD (data not shown). The percentage of total cells per coverslip with one to five or more than five processes is shown in Figure $11 B$. Inhibition of JNK activity with SEK1KR or JIP-JBD leads to an increased proportion of cells with four or five projections from the cell body and fewer cells with only one or two processes. Expression of the more effective JNK inhibitor, JIP-JBD, leads to a twofold increase in the proportion of cells with more than five neurites. Representative images are shown in Figure $11 C$. The increased number of processes per cell after inhibition of JNK activity may appear somewhat counterintuitive, given that increased JNK activity correlates with a period of increased neurite outgrowth. However, different neuronal subtypes in the brain have their own stereotypic number of processes, which is determined by a balance of positive and negative regulators (Tessier-Lavigne and Goodman, 1996). Because both the preexisting arbor and the cell body are potential sites for new process formation, the total negative regulation of outgrowth may be higher in more mature cells with increased arborization. Our data show that inhibition of the JNK pathway, after the onset of differentiation, reduces process number and may thus be one such negative regulator. 


\section{DISCUSSION}

A comparison of specific JNK activities from primary neurons, a neuroblastoma cell line, and non-neuronal cell lines reveals that cerebellar granule neuron-derived JNKs display considerable constitutive activity, exceeding that of stressed U937 cell JNK. Elevated JNK activity in primary neurons in culture was similar to the high activity detected in brain extracts prepared at the equivalent postnatal days (Fig. 4), implying that elevated JNK signaling may represent the endogenous state in the brain. Expression of dominant negatives of the JNK pathway that inhibit high basal JNK activity in CBG neurons leads to an increase in neurite number during the period of neurite outgrowth. This implies a regulatory role for JNK during neuronal morphogenesis. Upstream of JNK, basal activities of MKK4/7 were also elevated in brain and in CBG neurons (data not shown). We detect upregulation of JNK activity in cerebellar granule neurons during neuronal differentiation and in response to the classic activator of JNK, anisomycin. There are, however, striking differences between these two JNK responses. Developmental upregulation of JNK activity occurs in parallel with increased MKK4 and MKK7 activities, but in the absence of increased c-Jun phosphorylation (Fig. 5A). Anisomycin, however, activates MKK4, increases nuclear levels of MKK4, JNK, and active JNK, and strongly induces c-Jun phosphorylation. Thus, anisomycin-evoked JNK signaling has preferential access to c-Jun.

The developmental upregulation of JNK and MKK7 activity occurs without a parallel increase in protein expression, indicating that $\mathrm{MKK} 7 / \mathrm{JNK}$ activities are specifically induced during differentiation of these cells. The possibility that high JNK activity results from general stress associated with isolation of the cells is excluded because (1) the activity does not peak after isolation but gradually rises during the subsequent neuronal maturation, and (2) the stress-sensitive protein kinase p38 does not show such elevated constitutive activity, but its activity decreases during differentiation and is fully responsive to stressful stimuli (Figs. 1, 5). In addition, we have shown that culture medium supplements are not responsible for elevated neuronal JNK activity (Fig. 2). Cerebellar granule neurons are glutamatergic and are reported to maintain steady-state levels of $2 \mu \mathrm{M}$ glutamate from 3 to 7 DIV (Aronica et al., 1993). However, treatment of 1 DIV cells with the antagonists to NMDA, AMPA/kainate, or metabotropic-type glutamate receptors does not reduce the basal JNK activity. Furthermore, in low $\mathrm{KCl}$, extracellular glutamate is even lower outside the cells $(<1$ $\mu \mathrm{M})$ (Aronica et al., 1993), yet the increase in specific JNK activity still occurs (Fig. 6). The developmental increase in JNK activity observed in cultured cerebellar granule neurons is also detected in the cerebellum in vivo (Fig. $4 C$ ). The timing of this increase is retarded compared with the in vitro situation. This is possibly because plating of cells in vitro stimulates rapid and synchronous differentiation of all cells, whereas in vivo the cerebellum continues to produce new cerebellar granule neurons until postnatal day 21 (Burgoyne and Cambray-Deakin, 1988; Gao et al., 1991).

We have identified three pools of JNK activity in cerebellar granule neurons: a developmentally upregulated cytosolic pool, a developmentally upregulated nuclear pool, and a classic stress responsive translocating pool (summarized in Fig. 12). The high basal activity of $\mathrm{JNK}$ in cerebellar granule neurons is predominantly colocalized with MKK4 to processes, which places this developmentally upregulated JNK pool a considerable distance from the nucleus (Figs. 7, 8). This is consistent with the absence of increased c-Jun phosphorylation during differentiation that might otherwise be expected (Fig. $5 A$ ) and suggests a nontranscriptional role for the major pool of active $\mathrm{JNK}$ in the cell. However, the activity of the smaller nuclear pool increases 10-fold during differentiation, and yet c-Jun phosphorylation declines during this time, suggesting that the nuclear pool is also unable to act on c-Jun. A likely explanation is that the MKK $7 / \mathrm{JNK}$ binding scaffold protein JIP, which we detect with MKK7 in the nucleus (Fig. 10), sequesters nuclear JNK and prevents it from acting on c-Jun. JIP competes with c-Jun for JNK binding and has 100-fold higher affinity for JNK than does c-Jun (Dickens et al., 1997). JIP does not simply
A $\quad$ B

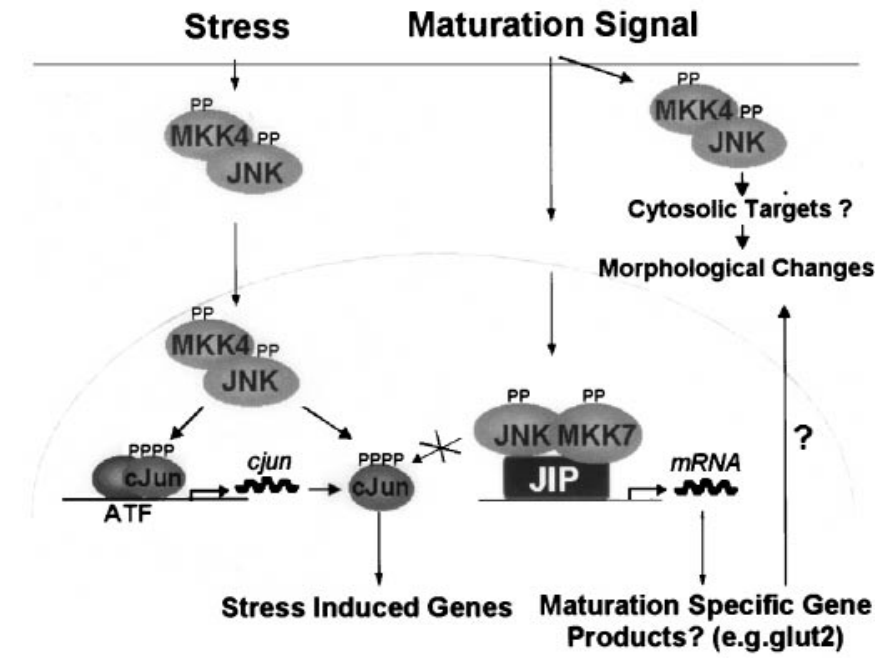

Figure 12. A model depicting the dual regulation of neuronal JNK signaling in cerebellar granule neurons in response to stress and during differentiation. In unstressed cerebellar granule neurons, JNK and MKK4 are localized predominantly in the cytoplasmic compartment. $A$, After treatment with the classic JNK activator anisomycin, MKK4 and JNK are activated, followed by their increased nuclear localization. Increased active JNK in the nucleus phosphorylates c-Jun, resulting in activation of stressinduced genes such as $c$-jun. $B$, During differentiation, cytoplasmic JNK (colocalized with MKK4) is activated threefold, and nuclear JNK (colocalized with MKK7) is activated 10-fold. Maintained localization of the major pool of MKK4/JNK activity to the cytoplasm suggests the presence of cytoplasmic JNK targets. Inhibition of JNK activity results in changes in neurite number, indicating a regulatory role for JNK signaling in morphological changes. JIP, a JNK-MKK7 scaffold that competes with c-Jun for binding to JNK, and MKK7 are colocalized in the nuclear compartment. This suggests a possible role for JIP in directing nuclear JNK activity away from c-Jun regulation and in upregulating maturation-specific genes.

inhibit JNK unless overexpressed (Whitmarsh et al., 1998) (Fig. $11 A$ ) but contains a putative DNA binding domain and has been shown to upregulate gene expression via a specific motif (Bonny et al., 1998). Thus JIP may be expected to channel JNK signaling away from the c-Jun/stress pathway, and perhaps toward expression of other genes (Fig. 12). The only currently known target for upregulation by JIP, the glut2 gene (Bonny et al., 1998), is a developmentally upregulated gene both in non-neuronal tissue, e.g., intestine (Miyamoto et al., 1992), and in the cerebellar granular layer (Nualart et al., 1999). We thus propose in our model that JIP might direct the developmentally upregulated nuclear JNK activity toward maturation-specific genes (Fig. 12).

Activation of the stress-sensitive JNK pool as detected from total cell lysates is moderate at $1 \mathrm{DIV}$, and yet c-Jun phosphorylation is strongly influenced by this stimulus (Fig. 3). The time course of anisomycin-induced JNK activation is typical of stress-induced JNK activation in other cell types (Iordanov et al., 1997). The small extent of the response and its disproportionate influence on c-Jun are thus most likely because the total activity of this pool with access to c-Jun is masked by the highly active developmentally regulated pools of JNK that do not have access to c-Jun (Figs. 5, 12). Consistent with this, the stress-responsive pool is revealed in mature neurons by isolating nuclear fractions, because the bulk of the high, developmentally regulated activity is cytosolic. In addition, isolation of nuclei reveals a clear activation and translocation of a proportion of JNK and MKK4 from the cytosolic fraction to the nucleus after treatment with anisomycin (Fig. 9A), correlating with subsequent c-Jun phosphorylation and mRNA expression (Fig. 3). The stress-sensitive pool of JNK may consist of a subset of isoforms showing a typical stress response. Ten isoforms derived from alternative splicing of JNK genes $1 / 2 / 3$ (rat SAPK $\gamma / \alpha / \beta$, respectively) have been identified in brain (Gupta et al., 1996) with 
overlapping mRNA distribution (Carboni et al., 1998). Although the subcellular distribution of isoforms in specific neuronal types is unknown, we have shown that multiple isoforms are expressed in cerebellar granule neurons in culture (Fig. $7 C$ ). Thus, the stresssensitive and developmentally regulated pools that we observe may consist of different subsets of isoforms.

The developmentally regulated pools of JNK activity increase sharply during the first week in vitro, a period during which cerebellar granule neurons thrive, generating a dense mesh of neurites (Fig. 5B), and mature into neurotransmitter-secreting cells (Thangnipon et al., 1983; Burgoyne and Cambray-Deakin, 1988). PC12 cell studies have also reported increased JNK activity during differentiation (Kobayashi et al., 1997; Yao et al., 1997; Eilers et al., 1998; Giasson et al., 1999). It is unclear whether the JNK MAPK enhances or impedes PC12 neurite outgrowth. p38 is also activated after NGF treatment of PC12 cells and is reported to be required for neurite outgrowth (Morooka and Nishida, 1998; Xing et al., 1998; Takeda et al., 2000). On the other hand, ERK MAPKdependent cJun activation is reported to be necessary for NGFinduced neurite outgrowth by some (Leppa et al., 1998; Klesse et al., 1999) but not by others (York et al., 1998). These conflicting reports may be the result of clonal variation rather than representing true neuronal properties. In cerebellar granule neurons however, c-Jun and p38 expression and activity decrease steadily during differentiation, suggesting that the signaling mechanisms regulating PC12 cell differentiation differ from those of cerebellar granule neurons. We have shown that blocking JNK activity in differentiating cerebellar granule neurons results in increased process number (Fig. 11). It is widely believed that both negative and positive regulators of neurite outgrowth exist that act together to determine the mature neuronal phenotype expressing both axon and dendrites (Tessier-Lavigne and Goodman, 1996). Our data suggest that JNK could be one such negative regulator.

In summary, we have characterized the anomalous behavior of JNK and JNK kinases in cerebellar granule neurons in culture. Our data show that a minor pool of cerebellar granule neuron JNK can show a classic response to stress resulting in c-Jun activation. The bulk of JNK activity, however, is dissociated from stress signaling and is upregulated during differentiation; the majority of this activity is in the cytoplasm with $\mathrm{MKK} 4$, and the remaining activity is in the nucleus with MKK7 and the JNK-MKK7 scaffold JIP. A possible role for JNK during differentiation is confirmed by the modulation of neuritic architecture after expression of dominant inhibitory regulators of the JNK pathway.

\section{REFERENCES}

Aronica E, Dell'Albani P, Condorelli DF, Nicoletti F, Hack N, Balazs R (1993) Mechanisms underlying developmental changes in the expression of metabotropic glutamate receptors in cultured cerebellar granule cells: homologous desensitization and interactive effects involving $N$-methylD-aspartate receptors. Mol Pharmacol 44:981-989.

Berberich I, Shu G, Siebelt F, Woodgett JR, Kyriakis JM, Clark EA (1996) Cross-linking CD40 on B cells preferentially induces stress-activated protein kinases rather than mitogen-activated protein kinases. EMBO J 15:92-101.

Bonny C, Nicod P, Waeber G (1998) IB1, a JIP-related nuclear protein present in insulin-secreting cells. J Biol Chem 273:1843-1846.

Bradford MM (1976) A rapid and sensitive method for the quantitation of microgram quantities of protein utilizing the principle of protein-dye binding. Anal Biochem 72:248-254.

Burgoyne RD, Cambray-Deakin MA (1988) The cellular neurobiology of neuronal development: the cerebellar granule cell. Brain Res 472:77-101.

Carboni L, Carletti R, Tacconi S, Corti C, Ferraguti F (1998) Differential expression of SAPK isoforms in the rat brain. An in situ hybridisation study in the adult rat brain and during post-natal development. Brain Res Mol Brain Res 60:57-68.

Cavigelli M, Dolfi F, Claret FX, Karin M (1995) Induction of c-fos expression through JNK-mediated TCF/Elk-1 phosphorylation. EMBO J 14:5957-5964.

Coffey ET, Akerman KE, Courtney MJ (1997) Brain derived neurotrophic factor induces a rapid upregulation of synaptophysin and tau proteins via the neurotrophin receptor TrkB in rat cerebellar granule cells. Neurosci Lett 227:177-180.

Coso OA, Montaner S, Fromm C, Lacal JC, Prywes R, Teramoto H, Gutkind JS (1997) Signaling from G protein-coupled receptors to the c-jun promoter involves the MEF2 transcription factor. Evidence for a novel c-jun amino-terminal kinase-independent pathway. J Biol Chem 272:20691-20697.

Courtney MJ, Lambert JJ, Nicholls DG (1990) The interactions between plasma membrane depolarization and glutamate receptor activation in the regulation of cytoplasmic free calcium in cultured cerebellar granule cells. J Neurosci 10:3873-3879.

Courtney MJ, Åkerman KEO, Coffey ET (1997) Neurotrophins protect cultured cerebellar granule neurons against the early phase of cell death by a two-component mechanism. J Neurosci 17:4201-4211.

Dai T, Rubie E, Franklin CC, Kraft A, Gillespie DA, Avruch J, Kyriakis JM, Woodgett JR (1995) Stress-activated protein kinases bind directly to the delta domain of c-Jun in resting cells: implications for repression of c-Jun function. Oncogene 10:849-855.

Dérijard B, Raingeaud J, Barrett T, Wu IH, Han J, Ulevitch RJ, Davis RJ (1995) Independent human MAP-kinase signal transduction pathways defined by MEK and MKK isoforms. Science 267:682-685.

Dickens M, Rogers JS, Cavanagh J, Raitano A, Xia Z, Halpern JR, Greenberg ME, Sawyers CL, Davis RJ (1997) A cytoplasmic inhibitor of the JNK signal transduction pathway. Science 277:693-696.

Dudek H, Datta SR, Franke TF, Birnbaum MJ, Yao R, Cooper GM, Segal RA, Kaplan DR, Greenberg ME (1997) Regulation of neuronal survival by the serine-threonine protein kinase Akt. Science 275:661-665.

Eilers A, Whitfield J, Babij C, Rubin LL, Ham J (1998) Role of the Jun kinase pathway in the regulation of c-Jun expression and apoptosis in sympathetic neurons. J Neurosci 18:1713-1724.

Gallo V, Kingsbury A, Balazs R, Jorgensen OS (1987) The role of depolarization in the survival and differentiation of cerebellar granule cells in culture. J Neurosci 7:2203-2213.

Gao WO, Heintz N, Hatten ME (1991) Cerebellar granule cell neurogenesis is regulated by cell-cell interactions in vitro. Neuron 6:705-715.

Giasson BI, Bruening W, Durham HD, Mushynski WE (1999) Activation of stress-activated protein kinases correlates with neurite outgrowth induced by protease inhibition in PC12 cells. J Neurochem 72:1081-1087.

Griffiths MR, Black EJ, Culbert AA, Dickens M, Shaw PE, Gillespie DA, Tavare JM (1998) Insulin-stimulated expression of c-fos, fra1 and c-jun accompanies the activation of the activator protein-1 (AP-1) transcriptional complex. Biochem J 335:19-26.

Gunn-Moore FJ, Tavare JM (1998) Apoptosis of cerebellar granule cells induced by serum withdrawal, glutamate or beta-amyloid, is independent of Jun kinase or p38 mitogen activated protein kinase activation. Neurosci Lett 250:53-56.

Gupta S, Campbell D, Derijard B, Davis RJ (1995) Transcription factor ATF2 regulation by the JNK signal transduction pathway. Science 267:389-393.

Gupta S, Barrett T, Whitmarsh AJ, Cavanagh J, Sluss HK, Derijard B, Davis RJ (1996) Selective interaction of JNK protein kinase isoforms with transcription factors. EMBO J 15:2760-2770.

Ham J, Babij C, Whitfield J, Pfarr CM, Lallemand D, Yaniv M, Rubin LL (1995) A c-Jun dominant negative mutant protects sympathetic neurons against programmed cell death. Neuron 14:927-939.

Han J, Jiang Y, Li Z, Kravchenko V V, Ulevitch RJ (1997) Activation of the transcription factor MEF2C by the MAP kinase p38 in inflammation. Nature 386:296-299.

Han TH, Prywes R (1995) Regulatory role of MEF2D in serum induction of the c-jun promoter. Mol Cell Biol 15:2907-2915.

Hazzalin CA, Cuenda A, Cano E, Cohen P, Mahadevan LC (1997) Effects of the inhibition of p38/RK MAP kinase on induction of five fos and jun by diverse stimuli. Oncogene 15:2321-2331.

Herdegen T, Claret FX, Kallunki T, Martin-Villalba A, Winter C, Hunter T, Karin M (1998) Lasting N-terminal phosphorylation of c-Jun and activation of c-Jun $\mathrm{N}$-terminal kinases after neuronal injury. J Neurosci 18:5124-5135.

Iordanov MS, Pribnow D, Magun JL, Dinh TH, Pearson JA, Chen SL, Magun BE (1997) Ribotoxic stress response: activation of the stressactivated protein kinase JNK1 by inhibitors of the peptidyl transferase reaction and by sequence-specific RNA damage to the alpha-sarcin/ricin loop in the 28S rRNA. Mol Cell Biol 6:3373-3381.

Ip YT, Davis RJ (1998) Signal transduction by the c-Jun N-terminal kinase (JNK): from inflammation to development. Curr Opin Cell Biol 2:205-219.

Janknecht R, Hunter T (1997) Activation of the Sap-1a transcription factor by the c-Jun N-terminal kinase (JNK) mitogen-activated protein kinase. J Biol Chem 272:4219-4224.

Jiang Y, Gram H, Zhao M, New L, Gu J, Feng L, Di Padova F, Ulevitch RJ, Han J (1997) Characterization of the structure and function of the fourth member of p38 group mitogen-activated protein kinases, p38delta. J Biol Chem 272:30122-30128.

Kawasaki H, Morooka T, Shimohama S, Kimura J, Hirano T, Gotoh Y, Nishida E (1997) Activation and involvement of p38 mitogen-activated protein kinase in glutamate-induced apoptosis in rat cerebellar granule cells. J Biol Chem 272:18518-18521.

Kelkar N, Gupta S, Dickens M, Davis RJ (2000) Interaction of a mitogenactivated protein kinase signaling module with the protein JIP3. Mol Cell Biol 20:1030-1043.

Kim IJ, Lee KW, Park BY, Lee JK, Park J, Choi IY, Eom SJ, Chang TS, Kim MJ, Yeom YI, Chang SK, Lee YD, Choi EJ, Han PL (1999) 
Molecular cloning of multiple splicing variants of JIP-1 preferentially expressed in brain. J Neurochem 72:1335-1343.

Klesse LJ, Meyers KA, Marshall CJ, Parada LF (1999) Nerve growth factor induces survival and differentiation through two distinct signaling cascades in PC12 cells. Oncogene 18:2055-2068.

Kobayashi M, Nagata S, Kita Y, Nakatsu N, Ihara S, Kaibuchi K, Kuroda S, Ui M, Iba H, Konishi H, Kikkawa U, Saitoh I, Fukui Y (1997) Ion of a constitutively active phosphatidylinositol 3-kinase induces process formation in rat PC12 cells. Use Cre/loxP recombination system. J Biol Chem 272:16089-16092.

Koleske AJ, Gifford AM, Scott ML, Nee M, Bronson RT, Miczek KA, Baltimore D (1998) Essential roles for the Abl and Arg tyrosine kinases in neurulation. Neuron 21:1259-1272.

Kumar S, McDonnell PC, Gum RJ, Hand AT, Lee JC, Young PR (1997) Novel homologues of CSBP/p38 MAP kinase: activation, substrate specificity and sensitivity to inhibition by pyridinyl imidazoles. Biochem Biophys Res Commun 235:533-538.

Kyriakis JM, Avruch J (1996) Sounding the alarm: protein kinase cascades activated by stress and inflammation. J Biol Chem 271:24313-24316.

Kyriakis JM, Banerjee P, Nikolakaki E, Dai T, Rubie EA, Ahmad MF, Avruch J, Woodgett JR (1994) The stress-activated protein kinase subfamily of c-Jun kinases. Nature 369:156-160.

Kyriakis JM, Woodgett JR, Avruch J (1995) The stress-activated protein kinases. A novel ERK subfamily responsive to cellular stress and inflammatory cytokines. Ann NY Acad Sci 766:303-319.

Leppa S, Saffrich R, Ansorge W, Bohmann D (1998) Differential regulation of c-Jun by ERK and JNK during PC12 cell differentiation. EMBO J 17:4404-4413.

Li Z, Jiang Y, Ulevitch RJ, Han J (1996) The primary structure of p38 gamma: a new member of $\mathrm{p} 38$ group of MAP kinases. Biochem Biophys Res Commun 228:334-340.

Marinissen MJ, Chiariello M, Pallante M, Gutkind JS (1999) A network of mitogen-activated protein kinases links $\mathrm{G}$ protein-coupled receptors to the c-jun promoter: a role for c-Jun NH2-terminal kinase, p38s, and extracellular signal-regulated kinase 5. Mol Cell Biol 19:4289-4301.

Meyer D, Liu A, Margolis B (1999) Interaction of c-Jun amino-terminal kinase interacting protein-1 with p190 rhoGEF and its localization in differentiated neurons. J Biol Chem 274:35113-35118.

Miller TM, Johnson Jr EM (1996) Metabolic and genetic analyses of apoptosis in potassium/serum-deprived rat cerebellar granule cells. J Neurosci 16:7487-7495.

Miyamoto K, Hase K, Taketani Y, Minami H, Oka T, Nakabou Y, Hagihira H (1992) Developmental changes in intestinal glucose transporter mRNA levels. Biochem Biophys Res Commun 183:626-631.

Mohit AA, Martin JH, Miller CA (1995) p493F12 kinase: a novel MAP kinase expressed in a subset of neurons in the human nervous system. Neuron 14:67-78.

Morooka T, Nishida E (1998) Requirement of p38 mitogen-activated protein kinase for neuronal differentiation in PC12 cells. J Biol Chem 273:24285-2428.

Mooser V, Maillard A, Bonny C, Steinmann M, Shaw P, Yarnall DP, Burns DK, Schorderet DF, Nicod P, Waeber G (1999) Genomic organization, fine-mapping, and expression of the human islet-brain 1 (IB1)/C-junamino-terminal kinase interacting protein-1 (JIP-1) gene. Genomics 55:202-208.

Moriguchi T, Toyoshima F, Masuyama N, Hanafusa H, Gotoh Y, Nishida E (1997) A novel SAPK/JNK kinase, MKK7, stimulated by TNFalpha and cellular stresses. EMBO J 16:7045-7053.

Mukherjee PK, DeCoster MA, Campbell FZ, Davis RJ, Bazan NG (1999) Glutamate receptor signaling interplay modulates stress-sensitive mitogen-activated protein kinases and neuronal cell death. J Biol Chem 274:6493-6498.

Nualart F, Godoy A, Reinicke K (1999) Expression of the hexose trans- porters GLUT1 and GLUT2 during the early development of the human brain. 824:97-104.

Park J, Yaseen NR, Hogan PG, Rao A, Sharma S (1995) Phosphorylation of the transcription factor NFATp inhibits its DNA binding activity in cyclosporin A-treated human B and T cells. J Biol Chem 270:20653-20659.

Pulverer BJ, Kyriakis JM, Avruch J, Nikolakaki E, Woodgett JR (1991) Phosphorylation of c-jun mediated by MAP kinases. Nature 353:670-174.

Raingeaud J, Whitmarsh AJ, Barrett T, Derijard B, Davis RJ (1996) MKK3- and MKK6-regulated expression is mediated by the p38 mitogen-activated protein kinase signal transduction pathway. Mol Cell Biol 16:1247-1255.

Sánchez I, Hughes RT, Mayer BJ, Yee K, Woodgett JR, Avruch J, Kyriakis JM, Zon LI (1994) Role of SAPK/ERK kinase-1 in the stress-activated pathway regulating transcription factor c-Jun. Nature 372:794-798.

Schafer H, Zheng J, Gundlach F, Gunther R, Schmidt WE (1996) PACAP stimulates transcription of c-Fos and c-Jun and activates the AP-1 transcription factor in rat pancreatic carcinoma cells. Biochem Biophys Res Commun 221:111-116.

Schwarzschild MA, Cole RL, Hyman SE (1997) Glutamate, but not dopamine, stimulates stress-activated protein kinase and AP-1-mediated transcription in striatal neurons. J Neurosci 17:3455-3466.

Takeda K, Hatai T, Hamazaki TS, Nishitoh H, Saitoh M, Ichijo H (2000) Apoptosis signal-regulating kinase 1 (ASK1) induces neuronal differentiation and survival of PC12 cells. J Biol Chem 275:9805-9813.

Tessier-Lavigne M, Goodman CS (1996) The molecular biology of axon guidance. Science 274:1123-1133.

Thangnipon W, Kingsbury A, Webb M, Balazs R (1983) Observations on rat cerebellar cells in vitro: influence of substratum, potassium concentration and relationship between neurones and astrocytes. Brain Res 313:177-189.

van den Heuvel S, Harlow E (1993) Distinct roles for cyclin-dependent kinases in cell cycle control. Science 262:2050-2054.

Wang TH, Popp DM, Wang HS, Saitoh M, Mural JG, Henley DC, Ichijo H, Wimalasena J (1999) Microtubule dysfunction induced by paclitaxel initiates apoptosis through both c-Jun N-terminal kinase (JNK)dependent and -independent pathways in ovarian cancer cells. J Biol Chem 274:8208-8216.

Watson A, Eilers A, Lallemand D, Kyriakis J, Rubin LL, Ham J (1998) Phosphorylation of c-Jun is necessary for apoptosis induced by survival signal withdrawal in cerebellar granule neurons. J Neurosci 18:751-762.

Whitmarsh AJ, Cavanagh J, Tournier C, Yasuda J, Davis RJ (1998) A mammalian scaffold complex that selectively mediates MAP kinase activation. Science 281:1671-1674.

Xia Z, Dickens M, Raingeaud J, Davis RJ, Greenberg ME (1995) Opposing effects of ERK and SAPK-p38 MAP kinases on apoptosis. Science 270:1326-1331.

Xing J, Kornhauser JM, Xia Z, Thiele EA, Greenberg ME (1998) Nerve growth factor activates extracellular signal-regulated kinase and p38 mitogen-activated protein kinase pathways to stimulate CREB serine 133 phosphorylation. Mol Cell Biol 18:1946-1955.

Xu X, Raber J, Yang D, Su B, Mucke L (1997) Dynamic regulation of c-Jun N-terminal kinase activity in mouse brain by environmental stimuli. Proc Natl Acad Sci USA 94:12655-12660.

Yao R, Yoshihara M, Osada H (1997) Specific activation of a c-Jun NH2terminal kinase isoform and induction of neurite outgrowth in PC-12 cells by staurosporine. J Biol Chem 272:18261-1826.

Yasuda J, Whitmarsh AJ, Cavanagh J, Sharma M, Davis RJ (1999) The JIP group of mitogen-activated protein kinase scaffold proteins. Mol Cell Biol 19:7245-7254.

York RD, Yao H, Dillon T, Ellig CL, Eckert SP, McCleskey EW, Stork PJ (1998) Rap1 mediates sustained MAP kinase activation induced by nerve growth factor. Nature 392:622-666. 